\title{
O QUE SIGNIFICA “OPERAR NO AMBIENTE”?
}

\section{WHAT DOES “OPERATE ON THE ENVIRONMENT” MEAN?}

\author{
SílVIO PAULO Botomé
}

\author{
UNIVERSIDADE FEDERAL DE SANTA CATARINA E \\ UNIVERSIDADE FEDERAL DE SÃO CARLOS, BRASIL
}

\begin{abstract}
1. Professor Titular (aposentado) dos Departamentos de Psicologia da Universidade Federal de Santa Catarina e da Universidade Federal de São Carlos. Bolsista-Pesquisador do CNPq.
\end{abstract}

Os quatro sub-títulos contém comentários a quatro artigos publicados neste volume especial (2013) da Revista Brasileira de Análise do Comportamento: "Um estudo sobre definições de comportamento" de Filipe Lazzeri, "Behavior and the skin" de François Tonneau, "O comportamento diante do paradigma behaviorista radical" de Kester Carrara e Diego Zilio e "O que não é e o que pode vir a ser comportamento" de João Cláudio Todorov e Marcelo Borges Henriques. Os artigos se referem a quatro exames relativos ao "problema" que representa o conceito de comportamento não apenas no âmbito das áreas de conhecimento da Psicologia ou das "Ciências Humanas", mas também nas demais áreas de conhecimento, assim como nos múltiplos campos de atuação profissional em que o conhecimento dessas áreas é utilizado.

Obviamente os comentários a esses artigos são parciais em relação às considerações apresentadas em cada um deles. Não caberia espacialmente, no âmbito do texto de um periódico, fazer um debate com abrangência e profundidade necessárias. Principalmente considerando as contribuições dos autores e as relações entre elas com a demonstração de sua localização e relevância para o refinamento e atualização do conceito de comportamento operante. Pelo menos daquele que é possível examinar com o conhecimento existente em meados da segunda década do século XXI. Os artigos mereceriam muito mais destaque do que lhes será oferecido por esses comentários, talvez demasiadamente superficiais até por limitações do comentarista, e apenas em relação a uma parte dos aspectos que os seis autores destacam como exame do conceito nesses quatro artigos.

No texto de Filipe Lazzeri (2013) um destaque importante: nem todas as definições, entendimentos ou concepções a respeito de comportamento referem-se ao que é objeto de estudo da Psicologia. O autor mostra a amplitude de usos do termo "comportamento" e as decorrências disso. Fica em destaque a pergunta: "qual conceito será o mais apropriado para delimitar o que é objeto de estudo e de intervenção da Psicologia?”. Os critérios e princípios envolvidos em uma definição (pelo menos segundo Copi, 1935/1978, conforme indicação do autor) são cruciais para a elaboração de um conceito que considere o que a pesquisa desenvolveu como conhecimento no âmbito do que Kester Carrara e Diego
Zilio (2013) vão considerar como "behaviorismo radical". Lazzeri destaca critérios (e princípios?) importantes a considerar em uma possível conceituação de "comportamento".

François Tonneau (2013) examina, em seu texto, o problema das interações e limites entre o que ocorre "sob a pele" dos organismos e o que é denominado de "ambiente". Os limites entre "organismo que se comporta e ambiente no qual o faz" é um problema relevante principalmente pela própria maneira de conceituar "limite" ou "fronteira". De forma particular quando se trata de um organismo que se comporta e esse processo é considerado no âmbito da Psicologia. Os critérios e princípios utilizados e destacados por Filipe Lazzeri (2013) são particularmente úteis também para a conceituação da "fronteira" entre organismo e ambiente que François Tonneau examina como um problema para entender (e talvez estender) o conceito de comportamento operante com a consideração do que acontece sob a pele, nela mesma, ou fora dela. Seria a pele de um organismo o "limite" ou "fronteira" entre organismo e ambiente?

Todorov e Henriques (2013) examinam o que consideram "que não é e o que pode vir a ser comportamento" questionando centralmente que seja a "interação entre organismo e ambiente". Nesse exame os dois autores utilizam e propõem vários conceitos que poderiam ser considerados como "subsidiários" (utilizando o termo apresentado por Carrara e Zilio, no artigo já referido) ao conceito de comportamento operante.

Nos quatro casos dos artigos em exame, o referencial maior, porém, é ajudar no esclarecimento ou explicitação de aspectos que precisam ser levados em conta ou integrados no entendimento ou no exame do conceito de comportamento, particularmente pelo que é entendido pelo termo "operante". Os quatro artigos podem ser considerados complementares e a junção deles, como contribuição, parece necessária. $O$ conjunto de artigos traz uma evidência importante: conceituar "comportamento" é um problema ainda controvertido e mais complexo do que aparenta. As contribuições de vários autores já aconteceram ao longo de muitas décadas desde a proposição inicial de Skinner (1938) com a primeira formulação do que seria o "comportamento operante". O conhecimento já foi mais desenvolvido - 
muito mais, embora esse grau de qualificação seja questionado por Tonneau no artigo citado - do que os trabalhos de Watson e Pavlov propiciaram entender no nascimento do século XX. Mesmo assim, parece que até a primeira metade da segunda década do século XXI, ainda é necessário muito mais exames e elucidações do que está envolvido com o conceito de tal fenômeno - o comportamento operante - e suas decorrências para a investigação, dele e de seus determinantes. Assim como o que está envolvido com seu uso de forma socialmente ampla e relevante, coerente com um conhecimento científico, eticamente responsável e filosoficamente coerente.

\section{"COMPORTAMENTO" PODE SER OBJETO DE ESTUDO DE QUALQUER ÁREA DE CONHECIMENTO E OBJETO DE INTERVENÇÃO DE MÚLTIPLOS CAMPOS DE ATUAÇÃO PROFISSIONAL 1}

Comportamento operante é muito mais do que mera atividade de qualquer organismo. E nomear isso de forma diferenciada é um problema ainda não resolvido no âmbito de conhecimento da análise do comportamento e do behaviorismo radical.

O texto de Filipe Lazzeri (2013) é, sem dúvida, um texto importante para o debate a respeito do conceito (e da definição) de "comportamento", particularmente na Psicologia. O autor mostra e destaca critérios para uma adequada definição (ou conceito) de um evento de qualquer tipo. Entre esses critérios estão os referenciais utilizados por quem elabora um conceito e os "objetivos" ou "finalidades" pelos quais alguém define um evento qualquer. O conceito (definiens) de algo (definiendum), segundo exame de Lazzeri, não é um amontoado de palavras às quais alguém já se acostumou ou que lhe são conhecidas. A "atividade" de quem define pode estar "orientada" por ("sob controle de" ou "em interação com") critérios, informações, "objetivos" (finalidades, intenções...) e procedimentos que variam de pessoa para pessoa e de circunstância para circunstância. A cada definição podem estar sendo considerados aspectos irrelevantes e não essenciais (Copi, 1953/1978) para a caracterização do evento em foco de acordo com o que é apresentado por Lazzeri (2013). As próprias circunstâncias podem, a cada conceituação, evidenciarem aspectos relevantes, ou nem tanto, para a construção de um conceito ou para a formulação da definição de um evento. Assim como os "objetivos" da mesma pessoa em diferentes condições podem levar a destacar o que é mais conveniente e não importante para destacar um evento de outros, como é o caso do que é considerado por alguém como básico em uma definição ou um conceito produzido em determinada circunstância.

No seu artigo a respeito de "definições de comportamento", Filipe Lazzeri (2013) usa e sistematiza critérios e finalidades indicados por Copi (1953/1978), ao realizar seu exame de vários "problemas com o

\footnotetext{
${ }^{1}$ Este texto é um debate propiciado pelo artigo de Lazzeri (2013).
}

entendimento de comportamento". O termo "comportamento", sem qualquer qualificação, é utilizado há muito tempo em uma amplitude muito grande de significados. Em geral, é usado como sinônimo de "atividade" de qualquer "organismo", mesmo os inanimados, para referir-se às transformações que eles apresentam em interação com outros "organismos". O texto de Filipe Lazzeri destaca tudo isso e indica vários problemas com múltiplas "definições ou concepções de comportamento". Particularmente são problemas sérios para a Psicologia, embora possam também sê-lo, de diferentes maneiras, para outras áreas do conhecimento, que usam o conceito de comportamento com referenciais diversos daqueles que a área (sub-área?) de conhecimento "Análise Experimental do Comportamento" evidenciou. E isso ocorreu juntamente com muitos esforços em um campo de atuação profissional que ficou abrigado pela mesma expressão: analistas do comportamento. Nela incluídos os cientistas que produzem o conhecimento básico presente em qualquer tipo de trabalho com o "comportamento", apoiados em um referencial de acordo com a microscopia e abrangência que circunscreve (ou delimita) a Psicologia de alguma forma (ver o exame de Tonneau - 2013 - a respeito dos limites como um problema na conceituação de algum processo ou fenômeno).

As mesmas complexidade e variedade de contribuições ocorrem com os conceitos de determinação do comportamento. Os conceitos de "causa" e "efeito" perdem sua utilidade com a noção de multideterminação de fenômenos que são compostos por variáveis diversas. Quanto maior a complexidade de um fenômeno ou processo, mais influências de diferentes variáveis e mais sensível a qualquer delas pode ser um ou outro aspecto componente do fenômeno. A Física Quântica não só trouxe contribuições relativas às influências na ocorrência de um fenômeno, como questionou a epistemologia científica, estendendo-se o questionamento às áreas do conhecimento a respeito dos organismos vivos (animais, senso-estrito e seres humanos). A tal ponto que incluiu a observação como parte das variáveis que interferem com a ocorrência do fenômeno observado. O que complicou ainda mais os problemas de definição ou conceituação, principalmente de processos que envolvem o comportamento humano. Com as contribuições de Sidman (1976) relativas ao processo de conhecer científico foi possível entender (e conceituar) o método da Ciência, passando da definição "controle das variáveis que interferem com o processo ou evento em investigação" para "controle das variáveis que interferem com o comportamento de conhecer algum processo ou evento" (ver maior detalhe deste exame em Botomé, 1993). A inclusão do processo de conhecer como uma das influências na ocorrência de um fenômeno é importante, particularmente no âmbito da Psicologia e no das ciências sociais, em virtude de o fenômeno de interesse ser fortemente influenciado pela presença do observador e o próprio processo de observação ser também fortemente marcado pelos referenciais de quem observa. Isso é aqui relembrado em função do processo de conceituar, uma 
classe de comportamentos que também é influenciada ou "induzida" (determinação probabilística) pelas circunstâncias de sua realização ou ocorrência.

No âmbito da Filosofia, Russell (1927/1969) apresentou o que pode ser considerado uma crítica muito clara e precisa ao conceito de comportamento que já estava presente no texto de Watson (1913). Russell destaca que o comportamento (ele examinava o "humano") não é apenas uma reação ao ambiente (e, nesse destaque, ele já salienta que está falando de uma interação quando utiliza os termos "comportamento" e "reação"), mas também é uma alteração desse ambiente que, por sua vez, alterado, afetará novos "comportamentos" do organismo. Para Russell, "comportamento" estava sendo utilizado nos termos em que Watson o fazia: como sinônimo de "resposta" ou atividade do organismo em relação a "estímulos". Skinner (1931), ao questionar o conceito de comportamento reflexo, colocou em dúvida que fosse a resposta, afirmando que era a "correlação entre estímulo antecedente e resposta do organismo". Pavlov considerou razoável o reflexo ser considerado como a "relação" (pelo menos, um tipo de correlação) entre estímulo e resposta, tanto no caso do reflexo incondicionado, quanto no do condicionado (Pavlov, conforme Pessotti, 1979, pp. 3959). Skinner, agora no âmbito da pesquisa empírica e da reflexão a partir de dados, investiga e demonstra, ao longo de vários anos, que Bertrand Russell tinha razão. Havia um fenômeno mais complexo e mais abstrato do que talvez Watson preferisse e Pavlov considerasse nas suas pesquisas pioneiras a respeito do reflexo de salivação e, em seguida, do reflexo aprendido (ou condicionado) por associação de estímulos no tempo e no espaço.

Skinner (1938) salienta, com a apresentação de muitas evidências, o conceito de "comportamento operante" como sendo o que é mais típico como fenômeno psicológico, respondendo ao que constituía o aspecto central da crítica de Russell em 1927, no âmbito filosófico. A palavra “operante”, em si mesma, já contém elementos importantes para identificar que há necessidade de haver uma análise do que está envolvido no que é "operado": o que está sendo objeto de transformação, quais as características das atividades que ocorrem em relação a esse objeto e que transformação ou resultado decorre dessa atividade em relação ao que existia antes dela ser realizada. Há três elementos (instâncias ou componentes) em interação e isso exige "análise" para identificar quais são esses três elementos (ou componentes de uma unidade).

E a análise em si, ainda é insuficiente. É necessário, como exigência de cientificidade, que seja demonstrado que os três componentes constituem uma unidade de interação. Por exemplo, "limpar algo" ou "decidir o que fazer em determinado momento" exigem que esteja claro o que está acontecendo antes da atividade (denominada pelo verbo, mas não descrita por ele), que características essa atividade tem e o que resulta dela. Nenhum dos três elementos é fixo, necessário ou constante (por isso são contingências), o que levou
Skinner a criar o conceito de classe de eventos: de estímulos antecedentes, de respostas, de estímulos consequentes e até de classe de comportamentos (Sério, 1983; Simonassi e cols., 2010; Skinner, 1931, 1935). O que amplia os limites do conceito e localiza algo mais central ainda: a ocorrência das atividades como uma característica diferenciada (de forma, intensidade, duração, força etc.) de qualquer atividade de um organismo vivo.

De forma complementar, Skinner trouxe o conceito de "reforçamento" para indicar que os eventos que se seguiam às atividades do organismo também eram circunstancialmente (contingentemente) passíveis de produzirem efeitos (equivalentes) na probabilidade de novas atividades similares (da mesma classe) ocorrerem em situações semelhantes (da mesma classe), quaisquer que fossem as "propriedades similares" (o que também seria uma contingência ou circunstância). A verificação foi elevada ao extremo de produzir a interação entre os três como evidência de que, de fato, eles constituíam uma unidade. A experimentação foi eleita como procedimento importante para examinar a nova "unidade" de um fenômeno instável, fluido, não físico por que era, fundamentalmente, uma interação entre atividades de um organismo e aspectos do ambiente a elas relacionados. É necessário, por isso mesmo, descobrir quais são esses componentes e quanto de cada um deles participa da interação, quais as características das atividades (movimentos, posturas...) dos organismos são responsáveis pela alteração nesses aspectos e quais são as transformações produzidas para poder, então, nomear (ou conceituar) qual "comportamento" está sendo realizado, ocorrendo ou está sendo desenvolvido em cada situação (que também precisa ser configurada). Isso tudo é crucial considerar para avaliar uma conceituação de "comportamento".

Um gesto ou toque físico de uma pessoa em outra será "acarinhar"? Precisa haver uma percepção muito clara dos três componentes que estão envolvidos para dar esse (ou outro) nome a qualquer comportamento. O mesmo gesto ou toque em uma ou outra circunstância pode ser algo desconfortável e desagradável, podendo até ser chamado de "grosseria". Ou, se o que ocorre com quem é alvo do toque ou atividade "denominada por acarinhar" for desconforto ou mal estar, como uma decorrência, isso faria dar outro nome (assédio, abuso, incômodo?) para o que está sendo feito, independentemente da intenção ou objetivo de quem faz o gesto ou toca outra pessoa. De forma semelhante, na atividade clínica ou no ensino, não há um objetivo de apenas "instalar respostas" (ou capacitar a pessoa a realizar atividades), mas de fazer isso em função de resultados (para o próprio organismo e para outros, em diferentes períodos de tempo) e em circunstâncias específicas (embora possa haver variações de um evento para outro). Criar uma nova interação entre classes de componentes ambientais antecedentes e decorrentes e um tipo de atividade de um organismo (seja ele humano ou animal) seria realizar uma síntese de novos comportamentos (novas interações entres esses três 
componentes) e isso também precisaria ser verificado e demonstrado. E, ao mesmo tempo, nunca poderia ser realizado sem ser precedido de "análise" ou descoberta dos componentes envolvidos na determinação (com sentido de influência, não de identificação precisa) no que está sendo realizado e daqueles eventos que precisariam compor o que precisa ser realizado por alguém em circunstâncias específicas. Novamente, isso tudo está envolvido na conceituação de "comportamento operante" e em suas implicações para os trabalhos de intervenção em "comportamentos". Pelo menos para os que possam estar reunidos sob essa denominação.

Os critérios apresentados no artigo de Filipe Lazzeri são indispensáveis para acompanhar o desenvolvimento de conceitos em Psicologia. Pelo menos aqueles com as contribuições e problemas nada pequenos que os conceitos de "comportamento operante" (Catania, 1973; de Rose, 2001; Schick, 1971; Sério, 1990; Skinner, 1938, Staddon, 1969; Todorov, 2002, 2012) e de "contingências de reforçamento" (de Souza, 2000; Skinner, 1969) trouxeram para entender e delimitar melhor os processos psicológicos, assim como os questionamentos exemplificados por Ribes (1989, 2000). Estes dois conceitos denominam unidades de interações complexas e exigem a identificação de seus componentes e a demonstração de que, efetivamente, constituem ou precisam constituir as unidades de interesse que possam ser denominadas pelos termos "comportamento operante" e por "contingência de reforçamento". A contribuição do conceito de operante não foi uma "explicação" do comportamento, mas uma contribuição para identificação e descrição de um processo que contribuía severa e visivelmente para as características de re-ocorrência de atividades de um determinado tipo (ou classe) de qualquer organismo vivo.

O exame dos critérios e referenciais realizado por Filipe Lazzeri (2013) evidencia que o "conceito de comportamento" ainda é muito mais parte do problema do que parte da solução para o desenvolvimento da Análise Experimental do Comportamento e o correspondente uso desse conhecimento em sínteses de novos comportamentos (Ferster \& Hammer, 1975), também verificadas e demonstradas. Nesses últimos casos, com um sentido muito diverso do de atividade, movimento ou postura, simplesmente. Isso não é pouco como exigência a ser atendida em qualquer trabalho de conceituação. E, embora existam critérios para avaliar uma definição e utilizá-los para delimitar o que é o "comportamento operante", a conceituação desse processo ainda parece ser uma tarefa a ser realizada e devidamente avaliada (ver contribuições de diferentes autores examinadas por Botomé, 1980, 2001) continuamente, à luz de novas descobertas científicas e de limitações na conceituação existente.

As definições propostas ao final do artigo de Lazzeri (2013), porém, parecem mais amplas do que aquilo que é a esfera de abrangência da Análise do Comportamento e as descobertas no âmbito da Psicologia, considerados os conceitos de "comportamento operante" e de "contingências de reforçamento". As contribuições de Lazzeri referidas (de 2013, apenas) não parecem incluir ou referir-se às descobertas específicas ao longo de várias décadas, no que diz respeito a esses dois referenciais. O que não diminui a importância da contribuição do autor para o entendimento do conceito de comportamento como um problema ainda a ser resolvido pela comunidade científica, particularmente a da Psicologia. O conceito em exame também é algo cuja delimitação precisa de uma contribuição bem fundamentada dos filósofos da Psicologia, particularmente dos que estudam as contribuições da Análise do Comportamento para o desenvolvimento da Psicologia como campo de atuação profissional e como área de conhecimento. No mínimo no âmbito da qualificação lógica dos conceitos em relação às descobertas científicas. O conceito de "comportamento operante" parece ser um excelente exemplo no qual os exames dos filósofos podem ser integrados, dada sua complexidade e consequente exigência para o trabalho de conceituação de tal fenômeno.

\section{COMPORTAMENTO OPERANTE: ONDE ESTÃO OS LIMITES DAS ATIVIDADES, DO ORGANISMO E DO AMBIENTE NESSE TIPO DE FENÔMENO? ${ }^{2}$}

\begin{abstract}
O que é "interno" e "externo" exige menos a definição do que seja um ou outro e mais a de qual seja a definição do limite ou da fronteira a separá-los.
\end{abstract}

O texto de Tonneau (2013) destaca vários aspectos importantes para identificar ou, pelo menos, lidar melhor, com os limites do que é organismo e do que é ambiente em uma interação (em que pese a necessidade de conceituação de "interação") entre atividade de um organismo e ambientes em que ela acontece e os que se seguem a ela de alguma forma (ver também Micheletto, 1997). A grande quantidade de aspectos que Tonneau indica e examina enriquece um conceito que, na maioria das vezes, é utilizado como se estivesse "congelado" no tempo ou como se Skinner o mantivesse com o mesmo conhecimento e elaboração que apresentou em 1938 no Behavior of Organisms. Carrara e Zilio (2013) salientam que há uma grande quantidade de conceitos (subsidiários) que precisariam ser examinados e esclarecidos para conceituar comportamento operante. E, tais exames e esclarecimentos, demandariam um volume e uma extensão de análises e definições que tornaria uma tarefa muito difícil ser realizada ou contida nas páginas de um único artigo. $\mathrm{O}$ texto de François Tonneau contribui com a lembrança de alguns conceitos que podem esclarecer ainda mais dificuldades do que uma definição em moldes mais usuais do que seja "comportamento operante".

Tonneau (2013) salienta que há certa continuidade e às vezes interpenetração entre ambiente $\mathrm{e}$ organismo, dificultando estabelecer limites rígidos ou específicos entre eventos que constituem um contínuo e,

\footnotetext{
${ }^{2}$ Este sub-título é um debate propiciado pelo artigo de Tonneau (2013).
} 
no caso do comportamento, um fluxo. É preciso salientar que, no exame que está sendo feito do conceito de comportamento operante, o conceito não é descritivo ou caracterizador de algo que se repete, mas é um conceito "instrumental" (refere-se a relações funcionais que precisam ser caracterizadas em circunstâncias ou contingências específicas). Significando o termo "instrumental" que ele serve para trabalhar ou operar com o evento quando ele acontece, não apenas em tese ou teoricamente (no âmbito do discurso ou dos "signos"). Isso é particularmente importante a partir do exame e da distinção feitos por Lewin (1935/1975) em relação aos "conflitos entre o modo Aristotélico e o Galilêico de pensamento na Psicologia contemporânea". Há vários conceitos que estão nos fundamentos das definições utilizadas para referir-se a comportamento que podem ser esclarecidos pelas contribuições de Lewin. Botomé (1980) detalha alguns desses conceitos e sua possível forma de contribuir para o exame do conceito de operante.

Uma das distinções presentes no texto de Lewin (ou derivada dele) refere-se à forma de entendimento e representação das áreas de conhecimento. Elas geralmente são entendidas e apresentadas como se fossem partes (ou cubículos) de um engradado, uma ao lado da outra (ou acima ou abaixo) com um "limite" (poderia ser uma analogia com "pele"?) bem definido entre elas. Uma representação mais adequada talvez fosse uma espiral que evoluísse do microscópico ao macroscópico, do simples para o complexo, do específico ou restrito ao amplo. Sem limites muito claros entre um e outro elo da espiral, representando as áreas do conhecimento em um contínuo e não em separações restritas e estanques. De tal forma, inclusive, que as mais amplas, mais complexas ou mais macroscópicas fossem constituídas (como combinação e não como "somatória") pelas anteriores em relação a essas mesmas escalas de grandeza, amplitude ou complexidade. Isso já exigiria que os conceitos fossem tratados de uma maneira diferenciada. Sem absolutizar apenas o que está dentro de alguma "fronteira" bem delimitada e fixa. Como é o caso do exame, problematizador, feito por Tonneau (2013) em relação ao "limite entre organismo e ambiente".

Lewin (1935/1975) também apresenta a noção de variável (algo que varia ao longo de graus) em oposição à noção de categorias fixas, estanques e opostas (muitas vezes com oposição até valorativa ou moral: certo $\mathrm{x}$ errado, virtude $\mathrm{x}$ vício, sadio $\mathrm{x}$ doente ou outros tipos de categorias com divisões nítidas e em oposição entre si). Ao conceito de variável, foi acrescido o conceito de "nível de mensuração". Tal conceito acarretou mais exigências, com maior precisão e clareza, a respeito de como pode variar qualquer propriedade de um evento, esteja ele sendo considerado em qualquer âmbito de microscopia ou de amplitude, magnitude ou complexidade. A própria distinção entre morfologia e função, por exemplo, conforme Tonneau (2013) examina, não comporta uma separação absoluta, como se a presença de uma implicasse na ausência da outra categoria. Isso é fundamental para não cair na tentação (que Lewin alerta como equívoco): separar os eventos como se as categorias de separação fossem fixas, rígidas, absolutas, permanentes ou estáveis e únicas e não um contínuo. Esses antigos conceitos, localizados e atualizados com as contribuições de Lewin, auxiliam a perceber que os problemas de "limites ou fronteiras" são importantes como evidencia o exame de Tonneau (2013).

Outro conceito também esclarecedor examinado por Lewin, e que vai ao encontro do exame de Tonneau no texto "Behavior and the skin", é o de multideterminação (ou "multicausalidade") dos eventos. Cada evento tem múltiplas variáveis componentes o que pode ser exemplificado ou ilustrado por um único e simples evento sonoro: ele tem timbre, duração, intensidade, tonalidade, frequência de ocorrência, altura... Se for feito um exame no plano da Física ele terá muitos comprimentos de onda. Como a cor... qualquer computador é capaz de ilustrar milhares de variações nas cores entre os limites do espectro que são percebidos por meio dos órgãos sensoriais. Se cada evento é complexo (composto por múltiplas variáveis que podem apresentarse em graus diversos), os possíveis determinantes (indutores) de sua ocorrência podem também ser múltiplos e influir cada um em diferentes variáveis componentes do evento em foco ou em algumas faixas de graus ao longo dos quais essas variáveis podem acontecer. Com esses conceitos, a possibilidade de entendimento ou de "explicação", previsão (ou controle) de algum evento é probabilística ou aproximativa. Isso foi problematizado, inclusive epistemologicamente, pela Física Quântica com a noção de que a própria energia envolvida na observação de um evento influi na ocorrência desse evento (Heisenberg, s.d.). Não há "caos ou incerteza" na natureza. Há uma aproximação probabilística no entendimento e explicação ou determinação dos eventos, de acordo com esse autor. E foi o que possibilitou entender até o uma possibilidade de mudança no conceito de método da Ciência: de "controle das variáveis que interferem no fenômeno que é examinado" para "controle das variáveis que interferem com o comportamento de quem realiza o processo de conhecer" (Sidman, 1976; Botomé, 1993; Nale, 1993). A própria noção de "determinação" na Física Quântica refere-se à precisão do cálculo matemático do grau ou ponto de ocorrência de uma partícula em algum momento. Para essa "determinação" (matemática) o cálculo envolveria a avaliação de gradientes de múltiplas variáveis interferindo na observação e no cálculo. Por isso a ambiguidade do termo "determinação". Ele não se refere ao que induz ou influencia a ocorrência de um fenômeno, no caso da Física Quântica, mas a possibilidade de "cálculo matemático preciso da posição (ou ocorrência) de um evento". Tais exames feitos pelos físicos quânticos e as decorrências epistemológicas delas, foram difundidos (ou distorcidos?) como "incerteza", "teoria do caos". E tudo isso acarretou também problemas para a elaboração de conceitos, principalmente quando é mais nítido que tais conceitos nomeiam processos, interações de algum tipo ou processos com algum grau de microscopia (ou macroscopia). Mais ainda se for 
considerado no que está cada delimitação conceitual de diferentes eventos, principalmente, se o evento de interesse for uma interação (ou relação) entre eventos.

Isso tudo, aplicado ao exame de Tonneau (2013), evidencia quão complexo pode ser o exame que esse autor provoca e quanto havia de problemas com as formulações iniciais de Skinner (1938). A própria noção de "contingência" utilizada por Skinner existe desde a Filosofia Clássica e já (ou também?) amplia o entendimento de "interação entre os eventos" uma vez que é sinônimo de "circunstancial": aquilo que é e pode não ser o mesmo evento (funcional e até morfologicamente em algum aspecto) em outra circunstância ou contexto. Isso tira a "fixidez" como uma das características desejáveis para o trabalho de conceituação. As definições, na Ciência contemporânea, tendem a ser funcionais (envolver os determinantes ou os componentes em situação contextualizada) e não apenas categoriais no sentido de fixar o que é eventual como se fosse um acontecimento fixo ou estável em suas propriedades morfológicas e funções ou interações. E isso ainda não se refere à explicação, no caso do comportamento e sua natureza.

Tonneau (2013), em uma parte de seu texto, salienta que Skinner (1938, p. 6) afirma que é mais desejável lidar com um "efeito" do que com o próprio movimento que o produz, embora seja mais fácil ou visível lidar ou considerar o movimento como o que é importante. No entanto, o que parece ser definidor do que o organismo está fazendo é dado (ou identificado), também pelo menos, pelo "efeito", resultado ou decorrência de sua atividade como organismo. Embora tal entendimento traga à tona todos os problemas apresentados por Tonneau a respeito desses conceitos (ambiente, organismo, limites entre um e outro, integração ou interpenetração entre ambos etc.). A conceituação do que é "fazer" vai ficar muito mais complexa se isso tudo for considerado como um problema para a conceituação de qualquer comportamento.

Os quatro critérios indicados por Tonneau, como utilizados ou considerados por alguns autores e pelo próprio Skinner em 1938 (1- o que o organismo está fazendo, 2- o que é observado que ele está fazendo, por outro organismo, 3- a parte do funcionamento de um organismo que interage com o mundo exterior e 4- o movimento do organismo ou de suas partes em um quadro de referência, formado pelo organismo ou por objetos, eventos ou campos de força externos a ele) mostram a exigência do exame de muitos conceitos para poder elucidá-los e nem sempre cada um deles (ou todos em conjunto) vai poder ser utilizado para definir um comportamento. É possível entender que Tonneau (2013) os considera critérios que aumentam a visibilidade para examinar qualquer definição de comportamento. Vale, porém, destacar - o que o Tonneau já faz - que não se trata de comportamento no sentido amplo que vale para qualquer movimento ou atividade de qualquer elemento animado ou inanimado (dos átomos aos astros ou galáxias, passando pelas substâncias, objetos, materiais, clima, vegetação, água dos rios etc.). O comportamento próprio de exame da Psicologia (o que não exclui nem os componentes mais microscópicos envolvidos nele, nem os contextos mais macroscópicos em que ele ocorre) é, pelo menos como propõe Skinner, o comportamento operante, enfatizando uma relação entre o organismo (o que está sob a pele?). E o próprio qualificativo "operante" já indica muita coisa a considerar além da atividade ou movimento (interno ou externo") do organismo.

Alguns exemplos de Tonneau (2013) bem problematizam isso quando, por exemplo, ele salienta que "cair em um precipício" não é comportamento, embora seja movimento ou deslocamento de um organismo (assim como do ar e de cada objeto existente junto ao corpo). O problema central, para examinar exemplos de operantes, é exemplificar um comportamento sem considerar o que, já para Skinner, era algo constituído por três contingências (três tipos de circunstâncias): os eventos que antecedem uma atividade ou movimento de um organismo, a própria atividade ou movimento e o que se segue ou decorre dessa atividade ou movimento. Voltando ao exemplo de Tonneau, a queda em um precipício pode ser a consequência de a pessoa ter saltado e o comportamento, neste caso, não é "cair", é "saltar", com a consequência de "cair" ou "o corpo ser deslocado" de um solo firme para um lugar em que não há solo para sustentar o organismo. Mesmo que a pessoa "caísse acidentalmente", precisaria ser examinado sob controle de que estímulos a atividade de caminhar (ou deslocar-se, ou segurar-se...) estava. Em um determinado momento ele pode caminhar sob controle (influência ou determinação) da paisagem e não sob controle do solo que tem sob os pés ou a segurança e firmeza do lugar em que pisa. Isso significaria algo equivalente a um comportamento inadequado de caminhar em um lugar com risco de queda. O comportamento operante, considerando todo o contexto e identificadas as contingências (no sentido de "circunstâncias", é conveniente reiterar) em curso, levaria a identificar outro comportamento (um comportamento de caminhar inadequado, sob controle da paisagem e não sob controle das características do caminho ou de suas adjacências?). Sem a explicitação e o exame das três contingências (três classes de eventos), explicitadas por Skinner como componentes de uma unidade de comportamento operante qualquer, será difícil dizer que o comportamento em exame é do âmbito da Psicologia. Isso reforça os problemas indicados pelo exame de Tonneau, mesmo que o exemplo esteja sendo ampliado com outros referenciais de exame.

O próprio termo "operante" já contém uma exigência ou pergunta que precisa ser respondida para que possa ser dito que o organismo "opera" (o que poderia ser sinônimo de atua, faz, produz...): em que aspectos do ambiente ele realiza sua ação, que características essa ação (atividade ou movimento...) tem, o que se segue e o que é produzido por ela e de que forma estão relacionados esses três tipos de eventos? Responder a essa pergunta ou atender às exigências que ela representa vai ao encontro dos critérios indicados por Tonneau que aumentam as possibilidades de enxergar 
melhor o que está envolvido nessa interação denominada pelo termo "operante" referindo-se ao comportamento de um organismo vivo. Uma máquina também opera (e ela precisará de matéria prima, de determinadas atividades ou movimentos e produzirá uma mudança nessa matéria prima), mas não é objeto da Psicologia (a não ser no âmbito dos comportamentos humanos que produzem a máquina ou controlam seu funcionamento). Mas não deixa de ser um processo que atende aos critérios enunciados por Tonneau, embora não seja um organismo vivo (e onde estaria o equivalente à "pele" de tal máquina?). A Engenharia de Produção (como conhecimento dos processos de produção) trabalha todo o tempo com processos desse tipo, o que envolve tanto áreas microscópicas (como a Física e a Química) quanto mais macroscópicas (como a Administração dessa máquina e seu funcionamento) ou psicológicas como os comportamentos humanos realizados que estão sob controle ("levam em conta") das propriedades dos materiais, das leis da Física, das regras de funcionamento da máquina, suas peças, sua organização e os resultados dos movimentos e trabalhos realizados pela máquina.

Uma atividade como "suar" ao receber uma informação ou notícia ruim (aversiva ou ameaçadora) é apenas uma parte do comportamento, agora no sentido psicológico. Precisa haver verificação de mais eventos para identificar no que (ou onde) está o comportamento operante e qual participação do "suar" há nele. Se for uma resposta ao evento aversivo que provoca alterações fisiológicas e sinaliza a possibilidade de mais eventos aversivos (como aumento de pressão, de tensão muscular etc., alterando o conforto do próprio organismo) a interação com esse evento será um comportamento operante. Mas tal denominação ainda depende de tais condições serem alteradas pelo organismo, diminuindo a pressão, a tensão muscular e recuperando algum grau de conforto fisiológico. Eventualmente, ainda tendo apoio ou proteção social (ou a sinalização de que isso ocorrerá quando houver tal tipo de situação aversiva) para enfrentar a condição ruim ou aversiva que se apresenta ou se apresentará. As condições para considerar se alguma atividade ou "reação" fisiológica será um comportamento operante, embora o organismo não o oriente e realize conscientemente, implicam em um bom grau de percepção da "fronteira" entre os processos que ocorrem "sob a pele" e o que ocorre "fora dela". O desconhecimento ou a desconsideração do que exatamente pode ser, em cada caso, os limites entre os eventos que Tonneau (2013) considera nos dois lados da fronteira - e talvez nela mesma - entre organismo e ambiente. Perceber ou identificar o que acontece nesses "dois lados" parece ajudar mais do que apenas separar "interno e externo" como se fossem independentes ou mutuamente excludentes ou um sendo ambiente e o outro sendo organismo e nada mais. Ajuda a identificar melhor o que pode (sob ou fora da pele) ser "resposta" ou "estímulo" em qualquer interação na qual esteja assentado o foco de exame. A consideração de possíveis, mas não estanques, "fronteiras" entre organismo e ambiente é algo que pode ajudar a considerar com maior clareza e precisão o que pode acontecer ao haver um cientista fazendo um estudo em laboratório. Tal processo envolve considerar, mais ou menos, as variáveis que isolou, controlou, desconsiderou ou ignorou em qualquer lado da fronteira. Talvez o que possa ser entendido por "organismo" não "termine" sempre nos limites da pele, nem o que é reunido sob a designação de "ambiente" tenha aí seu limite absoluto em relação a todas as atividades de um organismo. A condição do organismo, ao ter "reações" fisiológicas (inicialmente com predominância maior de processos talvez apenas fisiológicos) pode ser de conforto alterado ou variando em relação a uma condição ótima. Tal condição de conforto ("interna" ao organismo?) pode constituir parte de um comportamento operante que a altera junto, antes ou subsequentemente, a uma atuação no ambiente "fora da pele" do organismo. O exame de Tonneau salienta esses problemas e apresenta referenciais para um bom exame desse problema.

Tais condições e interações, no entanto, precisam ser verificadas e demonstradas. O que já é indicado pelo nome completo dos profissionais dessa área: "Analistas Experimentais do Comportamento". O "experimental" é a exigência de verificação e demonstração. O que exige a identificação dos componentes - análise - e a demonstração inequívoca (experimentação) de que estão em relação conforme os próprios conceitos em relação aos componentes de um comportamento operante. A mesma exigência é feita para o campo profissional no qual sejam feitas intervenções para desenvolver ou construir comportamentos novos ou diferentes. $O$ trabalho de intervenção exige análise e verificação de quais são os componentes envolvidos em um operante e no que precisam ser alterados para desenvolver um novo operante (que precisará de delimitação dos novos componentes). E, para realizar um procedimento que faça esse desenvolvimento acontecer, também há a exigência de verificação e demonstração (ou avaliação) se o novo comportamento (com novos componentes ou com interações diferentes entre os três componentes) decorre do procedimento utilizado, o que significa fazer uma síntese experimental do comportamento de interesse. Os nomes, clássicos, desde sua origem, parecem ser orientadores da conceituação de "comportamento operante". No entanto, sem análise (de algo composto), sem caracterização e verificação dos componentes ou sem demonstração inequívoca das interações existentes ou construídas não parece ser possível considerar que haja um trabalho com o comportamento operante, nem coerência com os critérios fundamentais do que constitui a "Análise Experimental do Comportamento", no sentido mais amplo do termo "operante". Seja "fora da pele", seja "sob a pele" de um organismo.

Mesmo podendo ainda ser mais descritivo e específico a respeito das exigências todas para o exame de um comportamento que possa ou não ser designado como "operante", Tonneau (2013) já mostra também esses problemas no exemplo da enguia que eletrifica outro organismo com atividade interna ao organismo (sob 
a pele, ou dentro dos limites morfológicos de seu organismo). Novamente, é possível encontrar os três componentes de um comportamento (ou os componentes de comportamentos que constituem vários elos - e não "causas internas" - de uma cadeia comportamental). O exemplo de Tonneau é similar a alguém que desenvolve pensamentos de que acontecerá algo aversivo no encontro com outra pessoa e, ao encontrá-la, age de uma maneira tensa e defensiva, fazendo o outro esquivar (evitar) ou fugir do encontro (que fica aversivo) ou do que poderia acontecer no encontro (sinalização de algo aversivo). A atividade neural do organismo é, nos termos de Tonneau (2013), "silenciosa" e imperceptível diretamente a um observador. Mas é passível ser descoberta por observação indireta (questionamento, aparelhos...). Um paralelo ao exemplo da enguia poderia ser feito com um toque de uma pessoa que produz uma excitação em outra pessoa: esse resultado não faz parte do que precisa ser considerado para nomear o que está sendo "feito" por alguém? Novamente é necessário mais do que apenas a atividade (tanto interna como externa aos limites morfológicos do organismo) para caracterizar se há um comportamento operante.

Os limites funcionais do que constitui um organismo podem ser muito diferentes dos morfológicos. Isso pode ser exemplificado pela aproximação da mão ao rosto de uma pessoa para verificar que conforme o contexto, ela afastará o rosto antes que a mão toque sua pele. Há uma distância que, em determinadas circunstâncias, pode constituir um "limite ou uma fronteira" entre o organismo e o ambiente e ela não é morfológica ou diretamente observável. Mesmo nesse exemplo, a distância, fronteira ou limite, precisa ser verificada e demonstrada ou haverá muita obscuridade em torno de definições e designações de qual comportamento está ocorrendo. Principalmente se forem feitos apenas a partir das suposições que o repertório de cada um influencia ou determina probabilisticamente (nos termos do exame de concepções galilêicas a respeito de indução de eventos examinados por Lewin, 1935/1975).

O organismo, utilizando um destaque de Tonneau (2013), não é uma agência todo o tempo. As expressões "emitir respostas" ou "emitir comportamentos", por exemplo, criam essa impressão e são expressões equivocadas ou equivocadoras (Baum, 2004, 2012). À medida que um organismo desenvolve uma interação com o ambiente, por meio de sua atividade, ele também passa a desenvolver movimentos (e até reações fisiológicas) sinalizados ou induzidos pelo ambiente na direção de uma determinada orientação que já foi "resultado" de atividades ou movimentos similares em situações também semelhantes. A partir desse processo o organismo poderá ser considerado uma "agência" para tais atividades (e comportamentos)? Antes de haver alguma força (ou fortalecimento) da interação entre os três componentes indicados, não parece apropriado dizer que o organismo é "sujeito" ou "agente". Ele apenas está em atividade e, ao fazê-lo, entra em interação com aspectos do meio que serão integradores (bem ou mal, mais ou menos, com interações mais fortes ou menos reforçadas, adequada ou inadequadamente...) desse fazer (atividades) em novas oportunidades similares. O que é observável são os componentes mesmo que indiretamente notados - de uma interação denominada pela expressão "comportamento operante". Mas precisa haver verificação e demonstração de que a interação existe e constitui uma unidade. "Pressão à barra" ou "bicar um disco", nos experimentos de laboratório por exemplo, já é algo que envolve a barra, o disco e alterações em ambos por meio da atividade desses organismos (rato ou pombo). E esses são exemplos de um elo de uma cadeia comportamental maior que poderia ser denominada de "obter alimento ou água" e que exigiria um detalhamento de todos os componentes de todos os comportamentos envolvidos em graus de microscopia ou de abrangência maiores do que aquele a que a linguagem usual se refere. Os comportamentos humanos complexos geralmente são desse tipo: extensas cadeias de comportamentos com muitas unidades entrelaçadas entre si por meio do resultado de uma unidade comportamental que passa a constituir uma situação antecedente que viabiliza outra unidade comportamental que, por sua vez, prossegue o processo que pode ser um comportamento complexo.

Escovar os dentes, tomar um banho ou planejar uma instituição (ou parte de uma) são exemplos desse tipo. O exame feito por Tonneau (2013) aumenta essas exigências de análise, verificação e demonstração para trabalhar, efetivamente, com o comportamento operante e não com derivações verbais do que é feito em laboratório para situações complexas sem os procedimentos fundamentais que caracterizam a Análise Experimental do Comportamento, em qualquer instância de trabalho com esse fenômeno, e o Behaviorismo Radical, como crítica, avaliação conceitual ou epistemológica e filosofia desse tipo de trabalho.

Várias contribuições (ver as examinadas por Botomé, 1980, 2001) já indicam que, quando o trabalho se refere ao comportamento operante, não se trata de lidar com relações entre organismo e ambiente (isso fica no conceito genérico de comportamento reduzido a "atividades", ou processos, dos organismos, substâncias e até objetos). Trata-se de uma relação (e isso é algo muito amplo ainda) entre três tipos de eventos. Mesmo atividades aparentemente apenas fisiológicas, se ocorrerem em determinadas circunstâncias (ou contingências) serão comportamento operante. Qualquer ser humano que já se sentiu mal em utilizar um banheiro sem higiene e conteve sua tendência a urinar ou defecar nesse ambiente, sabe que evitou um desconforto e suportou outro (fisiológico) de manter mais tempo o organismo tenso e desconfortável com fezes ou urina pressionando o reto ou a bexiga. Nesse exemplo, apesar de suas limitações, urinar e defecar, depois de aprendidos os respectivos controles esfincterianos, constituiriam comportamentos operantes ou não? Em que limites ou condições? No âmbito clínico, por exemplo, uma "encoprese" pode ser parte de um conjunto de respostas suprimidas por um ambiente extensa e diversificadamente aversivo, com muitos incidentes de punição? Ela poderia 
ser um comportamento operante sob controle de reforço negativo? E pode ser dito que ocorre sob a pele, em condições de controle neurológico "silencioso" do movimento dos esfíncteres? Tal tipo de "reação" do organismo pode ficar "crônica" (ou "naturalizada") e o organismo necessitar de aprendizado para distinguir (discriminar) as situações em que contração ou relaxamento dos esfíncteres pode acontecer sem comprometer a "sanidade" do organismo ou a higiene do ambiente?

Tais perguntas podem indicar que Tonneau (2013) traz uma contribuição, ou acentua um "problema", importante: o organismo e o ambiente podem ser "interpenetrados", co-dependentes e, de certa forma, com fronteiras difusas (ou não muito claras) entre eles, na medida em que a atividade que os reúne em uma unidade é um processo, um fluxo, tornando o comportamento algo que sempre precisará de uma análise que identifique e caracterize seus componentes e a forma como se relacionam ou como se desenvolve ou fortalece essa interação (ou se "enfraquece", incluindo todos os graus de "fortalecimento"). Nas palavras de Tonneau, o organismo não tem suas partes flutuando no espaço - nem tem suas atividades ocorrendo no vácuo - mas tem algo que lhes dá coesão espacial, morfológica ou funcional. As atividades ou movimentos e, em certo estágio, respostas de um organismo são, nas palavras de Skinner, "uma instância do comportamento". E elas foram, de acordo com a afirmação de Baer (in the begining there was the response...), em 1973, apenas um começo que provocou dedicação de esforços para entender e aprofundar o papel (a função) que exerciam na interação do organismo com seu ambiente, tornando mais claro o que constitui o processo ou fenômeno que recebeu o nome, durante muito tempo confusamente, de "psicológico". A contribuição de Tonneau, mesmo com a circunstancialidade em que este debate ocorre, é algo importante para o entendimento do que pode estar em que função em um comportamento. Isso será, constantemente, um problema a resolver.

Repetir ou fazer exegese do que Skinner falou ou escreveu na década de 1930 ou nas seguintes, não bastaria para desenvolver o trabalho de conhecimento a respeito do que ele revelou. Tonneau (2013) traz uma contribuição que obriga a mais exigências, além do que já houve em décadas passadas, no exame do que seja denominado como comportamento operante e a levar em conta uma amplitude maior de aspectos que podem ser considerados em qualquer um dos três componentes da interação. $\mathrm{O}$ exame de Tonneau parece possibilitar dois tipos de decorrência para os que trabalham com o comportamento operante: aumentam as exigências, mas também as possibilidades de clareza, precisão e demonstração de cada processo que for denominado pela expressão "comportamento operante".

\section{O QUE SIGNIFICA “OPERAR” NO AMBIENTE? O CONCEITO DE COMPORTAMENTO OPERANTE NO BEHAVIORISMO RADICAL RESPONDE? ${ }^{3}$}

\begin{abstract}
"Nenhuma ciência pode parar; se não puder manter o fluxo de descobertas, o aperfeiçoamento das interpretações, o refinamento dos procedimentos e a ampliação de sua abrangência, ela definhará.” (Sidman, 2005)
\end{abstract}

“O que é básico não é, contudo, sagrado. Teorias se sucedem, mudando o que é básico, pondo em tela o que se admitia - tanto os termos como as asserções”. (Hegenberg, 1974)

A amplitude de abrangência de qualquer palavra, termo ou expressão pode ser muito grande. Quanto mais ampla, mais ela envolverá e menos será possível demonstrar a veracidade de qualquer expressão ou termo nessas condições. No entanto, graças a essa amplitude, eles serão muito mais envolventes e sedutores. Talvez por isso a polissemia das metáforas seja importante e atraente na literatura: elas envolvem o leitor no significado que ele próprio der ao termo. Se alguém disser "vai chover", isso dificilmente será provado como não verdadeiro. Em algum lugar, em algum momento, em algum grau "vai chover" e por mais microscópico que isso seja, torna a asserção verdadeira. Se alguém, por outro lado, disser "vai chover, amanhã, entre 11:00 horas e 11:15 horas, tal quantidade, na esquina da rua $\mathrm{x}$ com a rua $\mathrm{y}$ ", isso é verificável e pode ser demonstrado como falso ou verdadeiro. Mas, perderá muito do "envolvimento" do ouvinte que a expressão "vai chover" possibilita.

Uma asserção necessita ser verificada na sua correspondência com o que acontece ou pode ser uma mera ficção verbal. A possibilidade de verificação, científica ou lógica, porém, "tira" muitos graus do "poder de atração e envolvimento" de uma afirmação. O termo "comportamento", de maneira similar, é amplo demais para ser utilizado sem maior especificação do que ele está referindo. Seu uso como sinônimo de atividade (em alguns casos como sinônimo de "resposta" ou "desempenho") pode ser desastroso. Pelo menos como denominação de um processo psicológico. Principalmente por englobar muito e esclarecer pouco. Todos os organismos, tanto os ditos animados quanto os inanimados, estão em atividade de alguma forma: deslocam-se, aproximam-se ou afastam-se de outros, desgastam, quebram, caem... além de, movimentar-se, olhar em uma ou outra direção, decidir, amarrar sapatos, escovar os dentes, fazer planos, redigir um texto, saltitar ou caminhar... Mesmo que, em muitos casos, o termo "atividade" seja utilizado como sinônimo de "movimento", "postura", "atuação", "ação" ou até "desempenho" (que têm significados ou referenciais muito diferentes).

\footnotetext{
${ }^{3}$ Este sub-título é um debate propiciado pelo artigo de Carrara e Zilio (2013).
} 
A pergunta que se impõe, para os objetivos deste texto é: quais as diferenças entre atividade e comportamento, pelo menos no âmbito da Psicologia? Existem? Carrara e Zilio (2013) examinaram parte importante desse nada simples problema em "O comportamento diante do paradigma behaviorista radical". Neste texto vão ser examinadas e debatidas algumas asserções desses autores. "Algumas" em virtude de a quantidade de aspectos examinados pelos autores e o referencial bibliográfico por eles utilizado exigir um texto de porte maior do que este texto ou a capacidades deste autor comportam.

Como Carrara e Zilio (2013) comentam, o termo "comportamento" não só tem uma longa história de uso, como esse uso tem sido largamente feito por múltiplas áreas de conhecimento para referir-se aos processos que sofrem ou realizam seus objetos de estudo ou parte deles (por ex. Stein e cols. 1993, Araújo Silva e col., 2007, para ilustrar o uso em Neurociências). E, com esse uso, ele adquiriu tantos significados que sua amplitude de abrangência não possibilita mais seu uso como objeto exclusivo da Psicologia. $\mathrm{Ou}$, por outro lado, não corresponde ao que foi descoberto e evoluiu com o trabalho da área de conhecimento específica que recebeu a denominação de "Análise Experimental do Comportamento". Nela, "definiens" (a conceituação) e "definiendum" (o objeto de conceituação) são de certo grau de especificidade (em oposição a muita amplitude) e têm características e propriedades que, com o próprio desenvolvimento das descobertas dos pesquisadores e filósofos da área, desenvolveram-se e se evidenciaram como extraordinariamente complexos, pelo menos em trabalhos ao longo dos últimos setenta anos, até a primeira década do século XXI.

Não se trata nem sequer de fazer um levantamento e avaliação crítica das definições existentes ou possíveis (Hegenberg, 1974), algumas apresentadas por Lazzeri (2013), ou dos critérios e objetivos na elaboração de definições (Copi, 1953/1978). Menos ainda, examinar e classificar ou organizar as múltiplas propostas ou usos feitos para o termo comportamento, mesmo entre os profissionais analistas do comportamento (De Rose, 2001; Ribes, 2004; Tourinho, 2006; Todorov, 2012, por exemplo). Isso apenas levaria a um levantamento das concepções utilizadas, não necessariamente a uma avaliação do que as descobertas possibilitaram elaborar a respeito do conceito de comportamento, particularmente o que Skinner denominou de "operante". Segundo Carrara e Zilio (2013), "examinar termos, no sentido oferecido por Skinner (1935), implica deter-se na caracterização de relações funcionais. Olhar para essas constitui tarefa sobremaneira psicológica, mais que lógica, implicando, na ótica do comportamentalismo, identificar as instâncias inseparáveis da contingência tríplice" (itálicos adicionados). Essa última parte da frase (em itálico) é crucial para examinar o que Skinner vai considerar uma "unidade de comportamento", embora isso ocorra mais tarde em sua produção científica e de uma maneira ainda confusa em função de o autor, muitas vezes, manter um uso indistinto dos termos "resposta" (ou classe de respostas) e "comportamento". Também sem haver uma consideração do problema da extensão do conceito de "classe" para o conceito de "comportamento" em diferentes amplitudes que alguma "unidade de comportamento" pode ter. Pelo menos para fins de caracterização ou de intervenção em tal tipo de processo, o comportamento operante, particularmente o humano.

Um destaque inicial - sob a forma de uma pergunta - parece importante para esclarecer uma orientação (talvez básica) do exame que se seguirá: pode uma interação, de qualquer tipo, ser objeto de definição? Seja ela uma interação entre objetos (por exemplo, proximidade, distanciamente, posição) ou entre processos (atrito e durabilidade ou desgaste de um objeto, escovar os dentes, desenvolver placas dentárias, escolher entre duas ou mais alternativas)? Considerando que qualquer relação entre dois objetos é também interação, mesmo que um deles seja "passivo" nessa relação (passivo é um termo que caracteriza um tipo de "atuação" na relação e, entendido assim, na interação). Marcadamente, é costume considerar interação, quando os componentes de um processo exercem, um em relação ao outro (ou uns em relação a outros), influências ou processos recíprocos. O termo interação será utilizado a seguir, preponderantemente, neste último significado, mesmo que as influências ou processos não ocorram no mesmo momento ou local. A pergunta é ainda mais importante quando os processos em interação são abrangentes. Imagine-se, por exemplo, elaborar um plano de governo de uma instituição (mesmo pequena). Essa classe de comportamentos, que envolve muitas cadeias de comportamentos (e cada elo dessas cadeias com classes de estímulos, classes de respostas e classes de consequências específicas) importantes para construir um plano de trabalho apropriado para o desenvolvimento, sucesso e contribuição social da instituição. O que seria uma unidade de comportamento nesse caso? O que seria utilizado para nomear cada parcela dessa unidade? Ou para nomear cada comportamento participante do sistema de cadeias comportamentais que constitui o complexo e amplo (uma classe de) comportamento denominado "planejar o governo de uma instituição" (ou elaborar o plano de...)? Poderia cada um ser denominado dessa forma e servir apenas para (à função de) apresentar aos eleitores e não para orientar (ou controlar) a atuação dos dirigentes em seu labor na instituição? Que função auxiliaria a nomear melhor tal tipo de "comportamento"?

Voltando à expressão "identificar as instâncias inseparáveis da contingência tríplice"; quais são tais instâncias, porque são inseparáveis, por que é necessário identificá-las para considerar o que é inseparável, por que são contingências? Carrara e Zilio (2013) destacam que não se trata de critérios de contiguidade (no espaço ou no tempo), mas de variação concomitante: a mudança em um acarreta mudança em outro. Ou seja, tais classes de eventos se definem (ou delimitam?) pelo tipo de interação que estabelecem entre si. $E$ as variações são circunstanciais (dependem de outros eventos que podem ou não ocorrer tanto quanto as variações ou mudanças) e 
por isso são "contingências" (são circunstanciais) e não fenômenos de uma natureza ou características fixas ou necessárias. Tais eventos, assim considerados, têm uma complexidade muito grande para serem examinados como uma unidade, em qualquer amplitude de abrangência, que seja constituída por componentes que são contingências (variam e não são de ocorrência necessária, podendo ser "fortuitas" ou na dependência de outros eventos ou até de objetos) ou circunstanciais (são definidas considerando as próprias circunstâncias em que ocorrem).

Um evento ou objeto qualquer, ou alguma característica deles, só pode ser considerado "estímulo" se estiver em determinada relação (ou interação) com outro evento (reação ou resposta de um organismo). Esse outro evento só poderá ser considerado "reação" ou "resposta" se estiver em determinada relação com o evento que está sendo denominado por estímulo, nessa relação ou interação. O tipo, a intensidade ou grau da participação de um ou outro nessa interação também são variados. Um evento (um objeto, um processo, uma pessoa ou o que outra pessoa faz ou produz...) pode ser apenas ocasião para ocorrência de uma atividade do organismo. A atividade do organismo pode apenas ocorrer quando o "outro evento" estiver presente. O outro evento poderá tornar-se estímulo quando, também por exemplo, uma determinada atividade do organismo produzir um resultado específico só, ou preponderantemente, na presença desse evento. Quando isso (uma relação do tipo "se...então..." específica - ver Souza, 2000) acontecer, o evento poderá ter uma função de "estímulo discriminativo" (indicador de oportunidade para a atividade do organismo produzir algo definido), que não é fixa ou necessária a não ser (?) nesse sistema de relações.

O mesmo pode ser dito a respeito da interação entre atividade do organismo e consequência dessa atividade, com muitas variações a respeito do que o organismo perceberá como "consequência" de sua atividade: resultados imediatos e contíguos, decorrências a médio ou longo prazos, eventos de diferentes tipos. $\mathrm{O}$ que será "funcionalmente consequência" capaz de fazer o organismo voltar a agir para produzir o mesmo evento poderá variar. A atividade do organismo terá uma de suas propriedades (a frequência de ocorrência), pelo menos, alterada pelas características desse evento que aparece como "produzido pela atividade do organismo": a probabilidade de uma atividade do mesmo tipo (classe) ser novamente realizada pelo organismo em circunstâncias similares (outra classe) àquelas em ele apresentou a atividade e que, depois da ocorrência desse evento "consequente", se tornam algo "sinalizador" de outro evento do mesmo tipo (ou de eventos da mesma classe).

Nesse rápido e simplificado exame aparece o que pode significar a expressão "identificar as instâncias inseparáveis da contingência tríplice". Quando as interações ocorrem elas podem, progressivamente ficarem mais "fortes" no sentido de os eventos antecedentes sinalizarem melhor ou mais precisamente, as atividades serem realizadas com maior rapidez quando o evento sinalizador ocorrer e as consequências serem produzidas com maior quantidade ou menos demora em relação às atividades do organismo. Cada um dos componentes de tal interação é uma contingência (uma circunstância) no sentido de que não necessariamente ser sempre o que constitui funcionalmente (naquele momento em que faz parte da) a interação e é também uma classe por poder variar em alguns graus suas características, mantendo sua função na interação. Se houver o fortalecimento dessas relações, em função das características do que $o$ organismo produz ou obtém por meio de sua atividade em um dado tipo de condição (classe de eventos), poderá ser dito que há "uma contingência de reforçamento". Mas, tal conceito já diz respeito a outro evento: a força das interações, quanto o ambiente está induzindo a frequência de alguma atividade obviamente também em alguma situação. É uma circunstância diferente: que tipo de indução o tipo de consequência (o que inclui variações no tempo entre a atividade e o que ela produz no meio) tem nas interações entre os três eventos constituintes. Elas ficam mais fortes? Mais fracas? Quanto?

Restam ainda algumas perguntas para ir ao encontro do texto de Carrara e Zilio: e a interação pode ser uma unidade? Pode ser nomeada e se tornar um tipo especial de evento (um processo, mesmo fluido, evanescente, não físico)? Qualquer papel social pode ser examinado com as mesmas perguntas. Ele só é um determinado papel (ou relação) em circunstâncias específicas. Mas não necessariamente o será se estiver em outras circunstâncias. "Marido" é o nome de uma interação de alguém com outra pessoa. Não é a pessoa ou sua natureza, ou sua identidade, ou sua personalidade. É um tipo de interação com outra pessoa e constitui uma classe ou unidade passível de exame, identificação e separação dos componentes que constituem tal interação de uma maneira adequada ou não, em qualquer grau. $\mathrm{O}$ mesmo pode ser dito para "esposa", "professor", "amigo", "amante", "motorista", "cirurgião", "reitor", "escritor", "cientista" ou "presidente". Examine-se a pergunta: um sofá pode ser combustível? E surgirá o problema da definição do que seja um sofá quando está queimando. Foi essa diferença (ou a ignorância dela) entre "ser" e "estar" que levou o Presidente Figueiredo a demitir o Ministro Eduardo Portela, quando ele comentou que "não era ministro; estava ministro". Se Figueiredo não estivesse presidente, não poderia demitir quem estava ministro. A diferença não é pequena, particularmente para distinguir um conceito de "relação fixa e necessária ou permanente" (uma concepção pré-galilêica para a natureza dos fenômenos - ver Lewin, 1935/1975) de outro a respeito de uma relação funcional, que dependerá de circunstâncias para ser delimitado como tal. Isso é coerente com o uso, por parte de Skinner, do termo "contingência" que, desde a Filosofia Clássica, significa "o que é e o que pode não ser". Ou que só é em determinadas circunstâncias, não tendo uma natureza fixa ou "uma essência" que determina suas propriedades de forma permanente nas interações com outros eventos.

Isso é salientado por Carrara e Zilio (2013) quando recordam o trabalho de Mach (1883/1915, 
conforme aqueles autores) ao propor como objetivos da Ciência não a busca de "causas" dos fenômenos, mas de uma busca das relações funcionais entre variáveis que participam do fenômeno. Carrara e Zilio prosseguem, destacando que Skinner adotou isso desde o início de seu trabalho: "As a scientific discipline (behavior analysis) must describe the event not only for itself but in its relation to other events...". Há nisso, pelo menos, dois problemas que acarretam confusões: é a relação (ou interação) uma unidade a ser decomposta (analisada) nos eventos que a constituem? A própria descrição (análise) do que constitui a interação tem potencial explicativo por explicitar o que é função do quê, na interação? E nisso tudo onde está o "comportamento"? Apenas nas atividades do organismo? Nas palavras de Carrara e Zilio, "intermediando as relações entre organismo e ambiente"? $\mathrm{Ou}$ o comportamento seria as relações entre os três componentes? Ou o conjunto de relações que se estabelecem entre os três componentes? As perguntas podem parecer sem nexo, a não ser que atividade, resposta e comportamento sejam considerados a mesma coisa e, então, ficaria "absurdo definir comportamento sendo ele mesmo parte do que é definido" (ver Todorov, 2012 e Todorov \& Henriques, 2013). Isso afrontaria, pelo menos o critério de circularidade comentado por Copi (1953/1978) e por Lazzeri (2013).

Ainda falta esclarecer que, entre as várias (são pelo menos seis tipos básicos apresentados por Botomé, 2013) interações dos três componentes, há uma delas com uma função que delimita, progressivamente (na medida em que ocorre e da forma como ocorre), pelo menos um aspecto das demais interações, fortalecendo-as ou enfraquecendo-as. Os eventos que se seguem às atividades do organismo em determinadas circunstâncias, além de possibilitar a delimitação que o organismo está fazendo, alteram a probabilidade de voltar a ocorrer atividades do mesmo tipo (classe de atividades). Especificamente, é útil acrescentar, voltarem a ocorrer em condições similares (classes de eventos antecedentes). Tais componentes, também progressivamente, tornar-seão mais fortemente "estímulos de uma classe" e "respostas de uma classe". E, como estímulos que antecedem novas oportunidades de atividades, serão uma espécie de indicador de eventos (de um tipo ou classe) subsequentes às respostas da classe de atividades. $\mathrm{O}$ evento que estiver presente e seus efeitos na configuração da interação entre os três componentes (graus de força) e na probabilidade da resposta voltar a ocorrer (um elemento físico que possibilita deduzir a força das interações) diante dos eventos da classe original, possibilitarão denominar com alguma precisão qual interação está ocorrendo. Como também o que a está mantendo (ou a construiu ou fortaleceu no passado). Assim como possibilitará definir novos componentes que poderão alterar essa interação atual - se ela for inadequada, prejudicial ou indesejável - em outra mais apropriada à vida das pessoas (ou animais, senso estrito) que dependem dessa interação entre três tipos de eventos. Por isso, os eventos que se seguem às atividades de um organismo em determinadas circunstâncias podem ser denominados de "contingências reforçadoras": elas interferem na força das interações entre os três componentes do evento de interação em exame. O conceito de "reforçamento" refere-se às interações que ficam mais fortes (ou mais fracas - o conceito de reforço refere-se a uma propriedade da interação que varia em um continuum).

Não é o comportamento que interage com o ambiente. É o organismo por meio de suas atividades que, por sua vez, sofrerão influência desse ambiente. Dizer que não é o comportamento que interage é correto se for algo diferente de atividade (ou, em determinadas circunstâncias, "resposta"). Mas, se comportamento for utilizado como sinônimo de resposta ou de atividade, permanecerá o problema de inconsistência em definir um todo pela parte dele. Imagine-se novamente: fazer uma incisão cirúrgica no abdômen de uma pessoa é uma unidade comportamental ou não? Se for, o que precisa ser levado em conta para denominar o que é feito pelo organismo para denominar isso de "incisão cirúrgica"? O que (e quanto) o cirurgião precisa levar em conta (apresentar atividades sob controle de quais estímulos) para fazer a incisão (onde exatamente, quanto de profundidade ou extensão, em que direção...)? O que deverá (ou precisará) ser produzido como resultado da "incisão"? Pode ser qualquer resultado sem comprometer o nome incisão cirúrgica para esse comportamento de "cortar um corpo humano de certa maneira em função de certas decorrências e levando em conta determinada condições"? Ou é a mesma coisa que "cortar" ou "fazer um corte em um corpo humano"? Apenas a atividade de cortar não delimita (ou caracteriza?), mesmo como nome geral, o que está sendo feito pelo organismo. Pelo menos não caracteriza o que está sendo feito sem reduzir o "fazer" à atividade que se evidencia mais do que a interação com os demais componentes a considerar na delimitação do que o organismo está, efetivamente, "fazendo".

Designar (ou nomear) um comportamento pela atividade não parece considerar o conceito de "operante". O termo "operar" (para qualquer atividade de um organismo) implica em fazer algo que mude um ambiente em outro ambiente (até o verbo "cortar", no exemplo, já indica haver uma alteração em algo por meio de alguma atividade de alguém). Sem um desses três aspectos será difícil nomear algo de "comportamento operante" e, menos ainda, nomear qual comportamento (não apenas atividade) está de fato ocorrendo. Além disso, a necessidade de verificar e demonstrar se, efetivamente, a interação existe, acontece ou foi construída com determinados componentes e se tem uma determinada força (está reforçada o suficiente para manter-se, por exemplo), é algo inerente a esse tipo de conceito complexo. Além de ser um conceito de algo fluido, evanescente, não físico, embora tenha componentes físicos e observáveis, mesmo que indiretamente. Além de serem tais componentes mutáveis em vários graus. A própria necessidade de verificação e demonstração, de certa forma inerente a esse tipo de evento - uma interação -, foi o que elegeu, para designação da área, como 
conhecimento, o termo "experimental" para um horizonte de maior potencial de demonstração da existência de interações e de quais tipos de interações. Não é por pouco ou por nada que a designação de "Análise Experimental do Comportamento" passou a existir em um determinado momento: algo é analisado em seus componentes. E para poder afirmar que as interações entre eles constituem "algo" (uma unidade de interação), os componentes e as respectivas interações precisam ser verificadas e demonstradas inequívocamente, como condição de identificar se é um comportamento, de qual comportamento se trata e como é constituído. E, passando desse conceito para o de contingência de reforçamento, identificar e demonstrar com que força se estabeleceram ou precisam ser estabelecidas as interações que estão existindo em um determinado recorte temporal ou circunstancial dessa interação. E, neste caso, tal força já é um evento (reforçamento) diferente das interações que configuram as demais interações existentes entre os três componentes. Não é esta última um objetivo do treino contínuo de um atleta para ele ter um "desempenho" apresentar um grau de uma interação complexa entre graus de seus movimentos e posturas com graus de aspectos do ambiente no qual ele "atua" -, por exemplo?

Um problema importante parece ser confundir "comportamento" com atividade (que pode chegar a ser "resposta" dependendo das contingências ou circunstâncias em que for realizada). E atividade é algo que é inerente aos seres, das partículas sub-atômicas às galáxias conhecidas no universo ou às relações de poder entre os seres humanos. $\mathrm{O}$ comportamento operante parece ser um "tipo" específico (sub-conjunto) de "comportamento" no sentido mais geral do termo (como atividade). O texto de Carrara e Zilio (2013) contribui com informações importantes para auxiliar no trabalho de problematização, desvendamento e formulação do conceito de "operante".

De qualquer forma, há para este autor, uma divergência na nomenclatura dada aos componentes de uma unidade de comportamento em qualquer amplitude que ela seja formulada: não parece ser adequado dizer que o "comportamento [no sentido do behaviorismo radical] intermedia a relação entre organismo e ambiente". O que faz isso são as atividades do organismo e, mesmo assim, isso não caracteriza apenas eventos psicológicos que consideraram as atividades do organismo como um todo. Sem isso, as atividades químicas, fisiológicas ou elétricas de um organismo também intermediam interações com o ambiente (alimentação, digestão, sonolência, funcionamento neurológico ou fisiológico em geral...). Isso, novamente, levaria a uma amplitude de entendimentos que esvaziaria a especificidade do conceito de "comportamento operante" dos organismos no âmbito da Psicologia. Embora possa haver atividades fisiológicas (ou interações entre "eventos e atividades" que podem ser considerados reflexos) que constituam parte dos componentes de uma interação operante. Principalmente como elos de uma cadeia que começa com a reação do organismo produzindo um estado corporal que pode, por sua vez, constituir um "ambiente antecedente" para outro elo da cadeia que pode ser alterar ou manter algo que está produzindo o estado corporal. A interação entre os três componentes já examinados, entre eles a atividade do organismo, precisa ser caracterizada como tal, desde o início do que pode ser uma extensa ou complexa "cadeia comportamental". Só é possível saber o que exatamente o organismo está fazendo, indo além de sua atividade física mais global ou aparente e indo muito além da designação que seja dada para tal classe de atividades. Por isso são marcantes, como referencial, as palavras de Donald Baer (1973), intitulado um artigo histórico: "in the begining there was the response...". Depois de seu início, a Análise do Comportamento, desenvolveu o conhecimento do comportamento operante e o seu potencial de construção de novas interações entre atividades dos organismos e ambientes nos quais essas atividades são realizadas.

\section{COMPORTAMENTO E INTERAÇÃO... OU INTERAÇÃO DO QUE COM O QUE? ${ }^{4}$}

Uma controvérsia pode ser originada por uma lacuna ou incoerência no conhecimento existente ou pelas instâncias lógicas e semânticas do discurso que expressa esse conhecimento. No caso do conceito de "comportamento operante" e do próprio contexto do estudo do fenômeno a que esse conceito se refere (a Análise Experimental do Comportamento) as controvérsias são inegáveis. Isso é esperado em relação a esse conceito e ao respectivo contexto de seu conhecimento, construídos ambos por muitos pesquisadores científicos e por filósofos ao longo de várias décadas e já ultrapassando quase um século de existência formal. Os textos e o debate produzido nos artigos publicados neste volume da REBAC a respeito do conceito de comportamento bem indicam algumas dessas controvérsias. Quanto existe de confusão semântica e quanto há de problemas conceituais, de fato e na percepção dos fenômenos em foco, parece ser um problema muito maior do que pode ser considerado em uma primeira aproximação aos problemas indicados pelos múltiplos autores que se dispuseram ao debate do conceito de comportamento. Isso tudo precisa estar presente em qualquer exame ou debate a respeito desse conceito. Principalmente para quem examina os textos alheios ou lê esse exame. O texto a seguir deve ser considerado com a lembrança desses cuidados, talvez para facilitar a identificação da relatividade ou das limitações do exame a seguir.

Em um breve exame do texto de Todorov e Henriques (2013) a respeito de "o que não é e o que pode vir a ser comportamento" destacam-se os conceitos envolvidos em qualquer tentativa de examinar o próprio conceito de comportamento operante e o referencial de trabalho no qual tal conceito está apoiado (a Análise Experimental do Comportamento). O entendimento do conceito de comportamento operante exige alguma

\footnotetext{
${ }^{4}$ Este sub-título é um debate propiciado pelo artigo de Todorov e Henriques (2013).
} 
concordância básica a respeito de outros conceitos envolvidos nesse entendimento. Uma grande quantidade de conceitos subsidiários, na expressão de Carrara e Zilio (2013). Para esclarecer melhor o que isso pode significar no esforço de debater um conceito (ou uma definição) de comportamento operante, mais como problema do que "como não é ou pode ser" tal fenômeno, é importante considerar que um conceito formulado por alguém é um tipo de formulação verbal que pode não considerar vários outros conceitos produzidos pelos trabalhos de muitos cientistas e filósofos, ao longo de algum período histórico que também precisa ser configurado. Mais ainda, é importante considerar transformações que contribuições de diferentes autores trouxeram ou acarretaram para a formulação de um conceito. $\mathrm{E}$ isso não é uma tarefa para um texto breve e limitado em espaço e tempo como o é este que está sendo lido. Carrara e Zilio (2013) já destacaram que "conseguir clareza terminológica dos termos de trabalho de um cientista configura-se como regressão infinita, onde o pesquisador teria a incumbência de explicitar definições de termos subsidiários empregados na definição do termo que constitui objeto central do estudo". Essa "regressão infinita" torna limitado o alcance que pode ter um exame adequado e profundo do que pode ser proposto como "exame ou debate" de possíveis contribuições de qualquer autor.

Em relação ao alerta de Carrara e Zilio, é necessário destacar também que há muitos graus de importância entre os múltiplos conceitos subsidiários (aproveitando o termo utilizado pelos dois autores) ao conceito de comportamento operante. Por exemplo, há conceitos básicos para delimitar o que pode ser considerado um comportamento operante (estímulo, classe de estímulos, resposta, classe de respostas, classes de estímulos antecedentes e de consequentes, reforçamento, contingência, contingência de reforçamento etc.). Há outros, melhor considerados como conceitos contextualizadores, que constituem referenciais para entender a própria inserção desse conceito em diferentes tipos de sistemas conceituais. Mesmo que não constituam uma teoria no sentido mais tradicional do termo: consequência, decorrência, subsequência, antecedente, sinalizador, facilitador, reforçador, evento aversivo, evento gratificante e outros. Todos para indicar diferentes referenciais ou recursos utilizados no trabalho de examinar conceitos envolvidos na definição de comportamento (particularmente se for o conceito for acrescido do termo "operante") ou na designação de algum processo como tal. Tais conceitos e seu uso ou exame exigem cuidados específicos porque ampliam a percepção e a complexidade além do que poderia ser uma nomeação de qualquer comportamento como se fosse uma unidade simples e não uma categoria de eventos. Uma categoria que pode expressar-se em um nome de uma cadeia de comportamentos, ou de uma mera sequência de respostas ou, mesmo, de uma sequência de comportamentos, sem identificação (ou percepção?) dos elos que fazem com seja perceptível e apropriadamente notado o que de fato ocorre sob qualquer designação que seja usada para algum comportamento.
Ainda há conceitos mais fundamentais como o de "análise", de "experimental" (frequentemente confundido com "pesquisa básica" ou com "pesquisa feita em laboratório"), variável, conjunto de variáveis, graus de qualquer variável, níveis de mensuração para especificar esses graus, variável "dependente", variável "independente", “causa", “efeito", “determinação absoluta", "determinação probabilística" "análise funcional", constituição de algum fenômeno, principalmente os que são mais complexos, como o comportamento. No uso ou exame de qualquer desses conceitos facilmente pode haver uma redução a concepções pré-galilêicas (Lewin, 1935/1975) para delimitar fenômenos ou processos e para examinar e identificar quais os "determinantes" de tais processos. Ou, com maior exigência, determinantes de cada um dos aspectos (variáveis ou classes de variáveis constituintes ou de variáveis componentes) de cada um desses processos. O exame de Carrara e Zilio (2013) parece ser mais do uma discreta advertência. Pode constituir um aviso para não haver exasperação com as limitações de qualquer texto com pretensões de "fechar o assunto" como se tal conceito não tivesse uma longa história plena de controvérsias e questionamentos que possibilitaram, por mais paradoxal que pareça, um desenvolvimento muito grande do conceito inicialmente proposto por Skinner no entendimento de "comportamento operante".

O texto de Todorov e Henriques (2013) a respeito de "o que não é e o que pode vir a ser comportamento", em que pese o "tom orientador" do título, está também sob as exigências de um conjunto de conceitos e uma história de sua construção muito complexas e específicas. Pelas próprias referências conceituais "subsidiárias", mesmo que muitas delas ainda estejam em construção. Por exemplo, concordando com os autores, definir comportamento como "interação do organismo com um ambiente" é uma regressão histórica e uma redução a um conceito amplo demais para circunscrever com clareza e precisão a contribuição específica dos estudos relacionados ao que foi considerado "operante" na história do conhecimento científico e filosófico em Psicologia. Mas também, dizer que as "abordagens, áreas, teorias, quando vistas na ótica da Análise do Comportamento, estudam interações que envolvem comportamento e ambiente", mesmo que se explicite que esse ambiente possa ser interno (biológico ou histórico) ou externo (físico ou social), é algo muito amplo para poder constituir uma delimitação do que seja o comportamento operante ou o objeto de trabalho da Análise do Comportamento. Até porque um "objeto de estudo" (ou de trabalho profissional) pode ser concebido, configurado ou delimitado em vários graus de abrangência e alguns desses graus podem ser imprecisos ou inadequados para localizar os eventos no foco e microscopia próprios de uma ou outra área.

A consideração de que "as fronteiras entre a Psicologia, como ponte que liga as ciências biológicas e as ciências sociais, não são delimitadas" torna a definição ainda mais vaga e imprecisa. A metáfora "ponte" não indica a especificidade das relações que estão envolvidas 
na constituição ou na determinação (relações de produção) do fenômeno comportamento. Variáveis envolvidas na determinação (probabilística, não absoluta) de um sistema complexo como o é qualquer interação, não são a mesma coisa que variáveis constituintes do fenômeno em estudo. A determinação (não no sentido de precisar matematicamente, mas de indução ou produção de um evento), inclusive, para ser entendida precisa ter as relações de determinação bem localizadas. Por exemplo, um evento subsequente (e isso já é um tipo de interação) de um tipo qualquer, com todas as variações que possa ter, não "causa" a ocorrência de uma resposta, mas influi fortemente (aumenta a probabilidade de ocorrência) em uma alteração da frequência das atividades da mesma classe depois que tal evento ocorrer. E se variarem as propriedades de tal evento, assim como variam as da história e das características do organismo que apresenta "a resposta" (ou uma classe ou tipo de atividade), a determinação da frequência das atividades do organismo, nessa classe, poderá ser considerada em uma direção tanto de aumento quanto de diminuição da mesma e em graus que também variarão em sentidos diversos. Só isso já delimita uma complexidade suficientemente grande para o exame de qualquer "interação" entre o que é constituinte e o que é determinante de qualquer das propriedades de um processo psicológico que possa receber o nome de "comportamento operante".

Um evento subsequente (independentemente de ser "efeito" ou "consequência") à atividade (de uma classe ou tipo) não "causa" essa atividade, mas influi nas características da frequência de ocorrências futuras das atividades desse mesmo conjunto (delimitado por sua relação com a subsequência). Não é "causa" da atividade (ou da "resposta" se estiver em uma relação definida com algum aspecto de um evento antecedente). Mas pode ser um determinante de alterações na probabilidade das atividades do mesmo tipo (ou classe). Alterações que se seguirão à contiguidade de um evento em relação às atividades dessa classe (ou "tipo"). Tal evento pode, inclusive, ser "sinalizador" de outro tipo de evento e pode ter suas propriedades originais alteradas pela associação com esse "outro tipo de evento" ("sinalizador", nesse caso!).

Essas considerações, ainda insuficientes, indicam já preliminarmente, a necessidade de considerar (e usar ou "estar sob controle de") muitos conceitos que precisam ser avaliados ou, minimamente, examinados. E, em relação a eles, haver um consenso de entendimento, mesmo que pequeno, entre os que debatem tais conceitos, quanto a seus referenciais. Ou haverá o risco de qualquer "debate" ser, mais precisamente, uma coleção de confusões semânticas e frases "indignadas" ou depreciativas dos argumentos dos oponentes, alicerçados em definições, talvez diferentes, de muitos conceitos "subsidiários" (ou intermediários) que são fundamentais para o exame ou uso de um conceito em foco. Particularmente se o conceito for da complexidade como é o de "comportamento operante" com as muitas contribuições, mais ou menos microscópicas, em estudos de laboratório, filosóficos e lógicos. Ou oriundas dos problemas encontrados no uso de tais conceitos em trabalhos profissionais. Há uma história de desenvolvimento do conhecimento, diretamente ou em muitos graus de aproximação, relativo ao conceito de comportamento que não é redutível ao que cada um "acha", "descobre pessoalmente" ou "improvisa circunstancialmente" para arrumar seu próprio entendimento das contribuições a que teve acesso. As considerações deste texto não são exceções a isso. E, vale destacar, a argumentação e demonstração apresentadas, não explicitam as fontes, mas indicam parte dos problemas que o estudo de várias delas pode ajudar a considerar ao debater, de fato, o conceito de "comportamento operante". Nem o uso de exemplos constituem argumentos, mas apenas ilustrações (que seja entendido assim!) dos problemas que tornam as exigências dos conceitos e argumentos de demonstração (talvez?) mais localizados nos eventos que possam servir de base para a elaboração do conceito em exame.

Quanto à expressão "as interações entre organismo e ambiente", Todorov e Henriques (2013) parecem concordar que não define ou delimita comportamentos, mas refere-se a interações de qualquer tipo: químicas, físicas, bioquímicas, sociais, culturais etc. Até mesmo uma pedra "cair" especifica que a pedra muda de posição em relação a qualquer aspecto do ambiente. E isso pode ser considerado como relação e até mesmo como interação: pode ser visto do "ponto de vista" da pedra ou dos aspectos do ambiente, diferentes em cada nova posição da pedra. E a expressão destacada no início deste parágrafo não especifica no que diferem tais interações daquelas que são objeto de estudo ou de trabalho de químicos, físicos, fisiólogos, sociólogos ou antropólogos e profissionais de outras áreas de conhecimento ou de campos de atuação diversos. Por exemplo: um corpo humano, em um túmulo, está em interação com o ambiente, mas não se trata de uma interação psicológica. Mesmo que seja acrescida a expressão "relações funcionais" para essas interações, não muda o problema. As relações entre um organismo humano (o que é mais, ou diferente, do que um corpo, do ponto de vista de diferentes áreas de conhecimento), em um túmulo, com o ambiente, mesmo as funcionais, não são "psicológicas" ou "comportamentais". Pelo menos não o são no sentido do conceito que Skinner apresentou como uma contribuição para a Psicologia ir além das interações entre "estímulos e respostas", conforme as contribuições que Pavlov identificou e Watson ampliou para além dos limites e condições do laboratório do respeitado cientista. $\mathrm{O}$ uso do termo comportamento em um sentido tão amplo não parece levar ao desenvolvimento do conceito específico de comportamento operante, elaborado por Skinner ao longo de sua vida profissional. Como cientista e construtor de várias (até lembrando que alguns consideram "sempre uma única e mesma") contribuições para o entendimento do que constitui e determina as diversas propriedades de um fenômeno psicológico, entendido como algo mais específico do que "interação entre organismo e ambiente" 
e algo muito mais complexo do que apenas "respostas a estímulos" ou "atividades" em si mesmas.

O uso do termo "desempenho" para referir-se às respostas de um organismo, por exemplo, refere-se a um determinado grau de frequência (ou outra propriedade) de respostas de uma classe em consideração a algum referencial (que pode ser outros graus dos mesmos eventos que constituem algum comportamento). Não é sinônimo de resposta (ou de atividade). Ou, no caso do uso por Todorov e Henriques (2013), nem de variações específicas (graus de variação) nas características das respostas de uma classe, além da frequência. A resposta não é uma variável, e nem sempre é dependente. Ela é algo com muitas propriedades (múltiplas variáveis), entre elas sua frequência de ocorrência (a latência, a duração, a intensidade etc. são exemplos de outras). Cada propriedade das respostas de uma classe é uma variável e é o conjunto delas que constitui uma "resposta" (ou atividade do organismo?) que pode estar em mudança de qualquer de suas propriedades. A relação com algum evento subsequente e contíguo a apresentação de cada "resposta" (ou atividade?) de uma classe será sempre algo a ser verificado. Quanto a essa relação é que cabe verificar se aquilo que segue a qualquer resposta de uma classe é algo produzido pela atividade do organismo, é algo que ocorre simultaneamente ou proximamente a essa atividade ou é algo que alguém apresenta artificialmente (e arbitrariamente) ao organismo quando ele realiza uma unidade da atividade em foco. $\mathrm{Ou}$, sendo algo que ocorre, não ser relevante para a delimitação do um comportamento operante específico. Tanto se alguém está se referindo ao que é percebido pelo organismo, ou ao que não o é, com variações e distorções nessa percepção ou falta dela. Isso não exclui a necessidade de delimitar classes de comportamentos de certa amplitude de abrangência que são consideradas como tais conceitualmente - por produzirem, as atividades nele envolvidas, eventos que ocorrem temporalmente distantes de tais atividades do organismo. Por exemplo: "limpar os dentes" não deixa de ser uma ampla classe de comportamentos que envolvem interações mais específicas entre tipos de atividades (com escova, com fio dental, com palito, com produtos químicos...) que não estão presentes no termo "limpar". Ele não se refere a uma atividade ou uma classe de atividades, mas a uma interação entre algo que existe (dentadura com resíduos de alimentos ou outras substâncias), alguma atividade do organismo (escovar, passar o fio dental entre os dentes, gargarejar com um produto, movimentar um palito nos espaços entre os dentes) e um resultado que é a remoção dos resíduos (dentadura sem resíduos de alimentos ou substâncias outras). Não parece apropriado (nem claro, nem preciso) nomear como "limpar" uma atividade que não é realizada em relação a esses resíduos (se os dentes já estiverem limpos, o que seria alguém "escovar" ou "limpar" os dentes?) ou que não produza um tipo e um grau de remoção de resíduos que possa ser considerado como "ausência de resíduos" nos dentes. Será ainda menos adequado se alguém chamar esse comportamento por apenas um verbo. "Limpar" nomeia muito mais do que apenas esse tipo de "limpeza" (imagine-se "limpar" com qualquer outro complemento diferente de "os dentes"). Qualquer um pode imaginar o grau de amplitude que essa maneira de conceituar ou designar um comportamento (mesmo que uma classe muito geral) teria para entender que aspectos estão constituindo, antes mesmo dos que estão determinando (induzindo?), essa classe de comportamentos de um organismo.

Descrever a atividade (movimentar a mão, segurar a escova, movimentar a escova de uma ou outra maneira...) é ainda menos esclarecedor. Só especifica atividades mais microscópicas (ou intermediárias?) em relação a outros aspectos existentes no ambiente ou a aspectos característicos dessas atividades (escova, posições dos dentes na arcada dentária, probabilidade de remover resíduos ou de apenas "atritá-los" nos interstícios dos dentes). Nomear qualquer comportamento operante apresenta esses problemas na constituição do próprio comportamento de quem "nomeia" ou "identifica" (mal ou nem isso) um comportamento. Esse problema é básico para qualquer trabalho de intervenção com o comportamento, particularmente o humano.

Quando Todorov e Henriques (2013) destacam que "comportamento não está no organismo, é parte daquilo que o organismo faz (citando Skinner, 1938) e, como tal, não pode ser a interação entre um e outro evento", exigiria um exame do que é considerado "fazer". Será difícil dizer que alguém $f a z$ algo específico, com apenas um exame da atividade do organismo. No exemplo em exame, para facilitar o raciocínio envolvido nessa conceituação, "limpar" não pode ser visto sem uma comparação entre o que existe e o que passa a existir como decorrência da atividade de um organismo (dente com resíduos, atividade do organismo em relação a isso e os dentes sem os resíduos). A especificação dos três componentes dessa interação (limpar os dentes) é necessária para nomear (e para identificar) o comportamento em exame ou de interesse. E o "fazer" já indicado por Skinner, exige mais do que apenas a especificação do tipo de atividade do organismo.

Designar algo como "desempenho", "fazer", "ação" ou outros termos equivalentes dependem da especificação dos três componentes já indicados para poder ser examinado nas propriedades específicas que definem esses termos. Mesmo em exemplos será difícil entender o que está sendo feito (ou coerência com o nome) sem identificar algum aspecto do meio que possibilita alguma comparação. Correr (em relação a caminhar, por exemplo, ou um deslocamento do corpo por meio do movimento de um determinado tipo e velocidade das pernas de um lugar para outro) é algo muito amplo e não indica o que está acontecendo de fato como comportamento. Designar algo como "fazer", sem especificar o que está sendo "resultado", constituirá emprego de um verbo vazio e genérico que diz quase nada a respeito do que está acontecendo. "Ação" entendida só como atividade do organismo indica muito pouco (o uso só de verbos dá uma falsa impressão de estar indicando "ações") do que está sendo realizado em relação ao ambiente que existe. E será difícil dizer que há 
alguma ação específica se não for considerado algum aspecto do ambiente.

Os exemplos são reveladores desse problema. Cair, queimar, quebrar... não indicam comportamento algum mas apenas nomes muito gerais de muitos tipos de coisas que sequer são sempre atividades de um organismo. Um organismo cair refere-se mais às consequências de um caminhar inadequado ou a um objeto deslocar-se ou ser deslocado de uma determinada posição para outra (uma comparação entre duas situações). Queimar ao sol não é ação de um organismo (a não ser que o Sol seja o sujeito dessa "ação") mas uma consequência de alguém expor-se ao sol (agora no sentido de raios solares) de uma maneira adequada ou nem tanto. Ou de certa maneira em certo horário, por certo tempo etc. O próprio resultado "queimado" só pode ser denominado se houver uma comparação com outro estado (antes do expor-se ao sol), caso contrário o expor-se ao sol não produz a queimadura, mas apenas (talvez) "ilumine" quem já estava "queimado" ou "bronzeado". "Bronzear-se ao sol" não parece ser a mesma coisa que "queimar-se ao sol" se for considerado o resultado de uma exposição à luz solar por alguém que obtém algum desses dois tipos de resultados.

Os exemplos podem parecer pueris, mas ilustram em um âmbito muito simples, uma complexidade que pode deixar alguém perplexo ou confuso quando tiver que proceder a uma análise de comportamento tais como alguns verbos indicam: decidir, planejar, governar, escolher uma alternativa, evidenciar alternativas para escolha, resolver problemas etc. Nesses casos os verbos são nomes gerais de sistemas comportamentais que envolvem até muitas cadeias comportamentais (e não apenas meras sequências de atividades ou de "respostas") de qualquer organismo animal, particularmente os humanos. Quando Todorov e Henriques (2013) diferenciam "consequência" e "efeito", há um problema a respeito da própria definição de um e outro conceito: dizer que "alguém acenar tem como resultado o deslocamento do ar e como consequência alguém acenar de volta" mistura várias instâncias de microscopia na especificação do que "está sendo feito por alguém em relação a algo". Usar o termo (ou nome) "acenar" já está dizendo que isso é feito em relação a alguém. E, portanto, já está pressupondo um "resultado" dessa ação que a definirá como tal. Se for apenas a atividade de balançar a mão há vários resultados que podem ser considerados: deslocamento do ar, afastar um diluir um cheiro desagradável, refrescar o ar em torno do rosto, cumprimentar outra pessoa a certa distância com um balançar das mãos etc. Parece desnecessário, para a análise de um comportamento, separar o que acontece no meio físico e o que é pertinente para afetar a atividade específica do organismo (cheiro desviado, temperatura atenuada, ou atividade de outro organismo em seguida a alguém movimentar as mãos). Em todos os casos há deslocamento de ar, mas não é este o aspecto ou evento relevante para o entendimento do comportamento específico, pelo menos no âmbito da Psicologia. Ou ele pode ser pouco relevante para avaliar a efetividade das atividades do organismo em sua apresentação em um determinado ambiente, embora seja importante para entender os processos que a atividade do organismo desencadeia no ambiente físico (qualquer movimento de qualquer organismo não desloca o ar?). Mesmo antes de considerar as alterações fisiológicas que estão envolvidas em cada processo (afastar um cheiro desagradável, diminuir a temperatura na superfície do rosto) ou não apenas físicos (sinalizar para outra pessoa a percepção e a disposição em relação a ela). Essas distinções (e conceitos "subsidiários" envolvidos) são fundamentais para o entendimento do conceito de comportamento operante e o de interações entre atividades de um organismo e o ambiente no qual essas atividades são realizadas em contraposição com o que é alvo de restrições por Todorov e Henriques (2013): a definição de comportamento operante como "interações entre organismo e ambiente". Sem dúvida esta última é uma definição genérica e pode ser inapropriada para designar o que foi que constituiu a contribuição que surge - mas não se esgota - com o conceito inicial de "comportamento operante" por volta do começo dos anos de 1940, por Skinner.

O exame exposto nos parágrafos anteriores não muda em relação a outro exemplo apresentado por Todorov e Henriques: a pressão de um rato na barra de uma caixa de Skinner em um tipo de experimento simples, que muitos já conhecem. Designar o que está sendo feito por um rato pela expressão "pressão à barra" já é indicar que o rato está exercendo uma atividade física em relação à barra com um resultado de alterar a posição da mesma até certo ponto (aquele no qual há acionamento de um circuito eletrônico) que, por sua vez, fará com que os mecanismos da gaiola se movimentem e com que uma porção de água fique acessível ao rato ou que liberará água no ambiente do rato. Tudo pode ser visto como resultado ou como consequência de um elo anterior de uma sequência de acontecimentos que estão planejados para acontecer dessa forma. É arbitrário o que será chamado de uma ou outra coisa em função de uma decisão anterior a respeito do que selecionar como "decorrência" importante para entender se o comportamento é "pressionar a barra" ou "produzir o que até então não estava presente" (água) em seguida à atividade de pressão a barra. Depois de algum tempo em um processo desse tipo, poder-se-ia dizer que o rato está "obtendo água" ou que está "saciando a sede" ou "diminuindo o desconforto da privação de água" ou "diminuindo o grau da privação de água", estes dois últimos exemplos comumente referidos como "sede". No que está, em suma, apoiada a designação do comportamento do rato nessa situação, examinada dessa forma em comparação com o exame inicial feito por Todorov e Henriques? O circuito ligado, o movimento dos mecanismos, a liberação de água, o acesso à agua, a redução do desconforto fisiológico e talvez outros eventos concomitantes ou em sequência temporal ou "de produção um do outro" são ilustrações da simultaneidade de eventos que podem ser encobertos pela nomeação, identificação ou classificação que os termos utilizados indicam. Pelo menos quando alguém denomina, de uma 
forma ou de outra, qual comportamento está ocorrendo (ou o observador considera?). Em qualquer dos exemplos examinados, é difícil delimitar (dar um nome ou especificar) o que está sendo "feito" pelo organismo (uma pessoa ou o rato, nos exemplos dos autores) sem especificar alguns aspectos do ambiente existente (classes de estímulos antecedentes) antes de uma atividade do organismo (classes de respostas) e em seguida (subsequência) às respostas dessa classe.

Todos esses termos estão cheios de exigências de especificação: quais aspectos do ambiente antecedente são importantes para configurar o "comportamento operante", quais propriedades ou características dos movimentos e posturas do sujeito são importantes para produzir algum tipo de resultado (ou consequência considerando a atividade ou movimentos e posturas do organismo como responsáveis pelo que acontecerá no ambiente), que tipos de subsequências são relevantes para configurar o comportamento operante em foco? Mais ainda, no âmbito da Psicologia, quais propriedades dos eventos ou de sua funcionalidade (um determinado tipo de interação) são importantes para distinguir "efeitos" de "subsequências temporais", de "consequências" ou de "decorrências" de uma atividade do organismo? Ou, variando a pergunta, quais dessas propriedades são importantes para caracterizar a interação entre atividade e ambiente de um organismo ou são mais apropriadas para identificar o fenômeno que será (ou foi) designado pelo termo "comportamento operante"? É importante reiterar: entre quais aspectos da atividade e do ambiente e não entre organismo e ambiente. Essa distinção é crucial, assim como o exame cuidadoso dos conceitos subsidiários (muitos outros ainda) ou intermediários envolvidos no conceito de "comportamento operante".

Respostas a qualquer uma dessas perguntas ainda exigirá o exame e delimitação de mais conceitos e um entendimento mais elaborado e específico a respeito das contribuições dos estudos relacionados ao comportamento operante do que os exemplos apresentados neste texto possibilitam. Tais tipos de exames e delimitações não são feitos para ignorar ou desconsiderar instâncias que estão em jogo, mesmo quando sejam da esfera da Física, da eletricidade ou da eletrônica, como "acionar os circuitos eletrônicos" de uma caixa de Skinner ou "deslocar o ar" com o movimentos das mãos. Eles são apresentados como procedimento para descobrir quais aspectos do ambiente ou da atividade do organismo são relevantes e em que grau de microscopia é melhor que sejam identificadas e especificadas para poder designar (isto também é conceituar) adequadamente o comportamento que está ocorrendo. Sempre além das características da atividade, em si mesma, de um organismo.

E nenhum desses muitos conceitos ainda pode ser considerado como "determinante do comportamento" sejam quais forem as variáveis ou conjuntos de variáveis que estejam sendo considerados. Se alguém quiser, especificamente, examinar os determinantes (probabilísticos) da atividade do organismo do rato, nesse último exemplo, terá que separar a determinação (reiterando, sempre probabilística!) da frequência da atividade em foco da determinação de outras características da mesma para produzir água. Outras características que estão relacionadas mais às possibilidades e limitações do ambiente (altura da barra, grau de resistência da mesma, formato da mesma, etc.), características do organismo (porte do organismo, força, privação, limites próprios da espécie - genética -, visão com limites suficientes para localizar aspectos do ambiente...) e outros que dependeriam da história de aprendizagem do organismo. No caso do exemplo do rato em uma caixa de Skinner, tais variáveis estão sempre relativamente controladas para não interferir, não determinar variações estranhas ao que está sendo estudado, examinado ou observado. Isso não significa que, por exemplo, o comportamento do rato possa ser tanto nomeado como "acionar o circuito eletrônico", "pressionar a barra", "movimentar o bebedouro", "obter água" ou "tornar presente uma gota de água em um determinado local da caixa", sem implicações para o entendimento - em qualquer grau de microscopia - do que está sendo "feito" pelo organismo. A simultaneidade de vários eventos é uma constância nos comportamentos do organismo. O que é selecionado em cada interação depende tanto do ambiente (mais ou menos evidente), tanto quanto do organismo (quanto ele consegue "tomar contato" com esse ambiente) seja por aprendizagem anterior seja por características da espécie (limites e possibilidades de visão, olfato, audição, gustativos, órgãos proprioceptivos...) ou por condições físicas e fisiológicas do organismo (privação de sono, de alimento, com lesão em algum órgão ou membro...). Um ambiente programado pode ser acessível a um estudioso ou pesquisador, mas não significa, por isso mesmo, que o organismo que se comporta tenha o mesmo acesso a esse ambiente. Assim como a percepção da própria atividade (com suas características físicas, anatômicas, fisiológicas, estruturais etc.) pode ser parcial, equivocada, mais ou menos precisa etc.

O parágrafo anterior pode ser uma amostra do que precisa ser cuidado em um debate ou exame de conceitos como os apresentados e examinados por Todorov e Henriques (2013) em seu texto com o título "o que não é e o que pode vir a ser comportamento". A quantidade de conceitos subsidiários envolvidos não possibilita um exame mais extenso ou profundo do que o que está sendo apresentado neste texto. Emprestando a expressão de Carrara e Zilio (2013), no artigo que foi que parte da origem destes comentários, seria necessária uma regressão a muitos conceitos subsidiários para examinar, com uma fundamentação satisfatória, toda a extensão ou complexidade do conceito de "comportamento operante".

A própria denominação "Análise Experimental do Comportamento" indica um objeto de "análise". Um objeto que, para ser analisado (entendendo isso como “separação em suas partes ou 'instâncias' componentes"), exige identificar quais são seus componentes. A verificação e demonstração exige, no mínimo, uma aproximação cada vez maior do que foi designado pelo termo "experimental", voltado para a produção 
sistemática - como demonstração inequívoca - de qualquer fenômeno que seja considerado uma unidade de comportamento (em análise nas suas partes componentes). A análise também será básica, prérequisito ou parte integrante de qualquer trabalho de construção ou desenvolvimento de um comportamento (neste entendimento: síntese de um comportamento). Talvez o exame dessa expressão, meramente exemplificado aqui, possa delinear a possibilidade de uma integração de tudo isso. Mas esse seria outro debate e tomaria muito mais páginas. $\mathrm{O}$ que não é proposto ou indicado para este texto, ainda periférico e talvez pouco passível de perdão por isso.

\section{REFERÊNCIAS}

Araujo Silva, M. T., Gonçalves, F. L., \& Garcia-Mijares, M. (2007). O nível neural na Análise do Comportamento. Em: J. Landeira-Fernandez \& M. Teresa Araujo Silva (Orgs.) Intersecções entre Psicologia e Neurociências. Rio de Janeiro: MedBook.

Baer, D. (1973). In the beginning there was the response. Em: E. Ramp \& G. Semb (Orgs) Behavior analysis: áreas of research and application (pp. 16-30). New Jersey: Prentice-Hall,

Baum, W. M. (2004). Molar and molecular views of choice. Behavioural Processes, 66, 349-359.

Baum, W. M. (2012). Rethinking reinforcement: allocation, induction, and contingency. Journal of the Experimental Analysis of Behavior, 97, 101-124.

Botomé, S. P. (1980). Objetivos comportamentais no ensino: a contribuição da Análise Experimental do Comportamento (Tese de doutorado). Instituto de Psicologia da Universidade de São Paulo, São Paulo.

Botomé, S. P. (2001) Sobre a noção de comportamento. Em: H. P. de M. Feltes \& U. Zilles. Filosofia: diálogo de horizontes. Editora da Pontifícia Universidade Católica de Porto Alegre e Editora da Universidade de Caxias do Sul.

Botomé, S. P. (1993). Metodologia de pesquisa: a lucidez orientando a ação. Em: T. R. S. Dias, F. E. Denari, \& O. Kubo. Temas em Educação Especial 2 (pp. 313324). São Carlos: Programa de Pós-graduação em Educação Especial da Universidade Federal de São Carlos, São Paulo.

Carrara, K., \& Zilio, D. (2013). O comportamento diante do paradigma behaviorista radical. Revista Brasileira de Análise do Comportamento, 9(1), 1-18.

Catania, A. C. (1973). The concept of the operant in the analysis of behavior. Behaviorism, 1, 103-116.

Copi, I. M. (1978). Introdução à Lógica (2a . Ed.) (A. Cabral, Tradut.). São Paulo: Mestre Jou. (Trabalho publicado originalmente em 1953). de Rose, J. C. C. (2001). O que é comportamento. Em: R. A. Banaco (Org.). Sobre comportamento e cognição: aspectos teóricos, metodológicos e de formação. Santo André (SP): Esetec.

de Souza, D. G. (2000). O conceito de contingência: um enfoque histórico. Temas em Psicologia, 8, 125-130.

Ferster, C. B., \& Hammer Jr, C. E. (1975). Sintesis de los componentes de la conducta aritmética. Em: W. K. Honig (Org.), Conducta operante: investigación y aplicaciones. México: Trillas.

Hegenberg, L. (1974). Definições: termos teóricos e significado. São Paulo: Editora da USP e Editora Cultrix.

Heisenberg, W. (s. d.). A imagem da natureza na Física moderna. Lisboa: Livros do Brasil.

Lazzeri, F. (2013). Um estudo sobre definições de comportamento. Revista Brasileira de Análise do Comportamento, 9(1), 47-65.

Lewin, K. (1975). O conflito entre os modos Aristotélico e Galilêico de pensamento na Psicologia contemporânea. Em: K. Lewin, Teoria dinâmica da personalidade (A. Cabral, Tradut.), São Paulo: Cultrix. (Trabalho publicado originalmente em 1935).

Mach, E. (1883/1915). The science of mechanics: a critical and historical account of its development. Chicago: Open Court.

Micheletto, N. (1997). Há um lugar para o ambiente? Em: Banaco, R. (Org.) Comportamento e Cognição. V.1 (pp. 29-44). Santo André: ARBytes.

Nale, N. (1993). A metodologia da pesquisa pode transformar-se em uma camisa-de-força para o pesquisador em Educação? Em: T. R. S. Dias, F. E. Denari, \& O. Kubo (Orgs.), Temas em Educação Especial 2 (pp. 304-312). São Carlos: Programa de Pós-graduação em Educação Especial da Universidade Federal de São Carlos, São Paulo.

Pavlov, I. P. (1979). O reflexo condicionado. Em: Pessotti, I. (org.) Pavlov. São Paulo: Ática.

Pessotti, I. (org) (1979). Pavlov. São Paulo: Ática.

Ribes, E. (1989). La psicologia: algunas reflexiones sobre su qué, su como, su porqué y su para qué. Em: J. Turbina (Ed.) El psicólogo (pp.847-860). México: UNAM.

Ribes, E. (2000). Las psicologias y la definición de sus objetos de conocimiento. Revista Mexicana de Análisis de la Conducta, 26, 365-382.

Ribes, E. R. (2004). Behavior is abstraction, not ostention: conceptual and historical remarks on the nature of Psychology. Behavior and Philosophy, 32, $55-68$. 
Russel, B. (1969). Delineamentos da Filosofia (B. Silveira, Trad.). Rio de Janeiro: Civilização Brasileira. (Trabalho publicado originalmente em 1927).

Schick, K. (1971). Operants. Journal of the Experimental Analysis of Behavior, 15, 413-423.

Sério, T. M. A. P. (1990). Um caso na história do método científico: do reflexo ao operante (Tese de Doutorado). PUC-SP, São Paulo.

Sério, T. M. A. P. (1983). A noção de classe de respostas operante: sua formulação inicial. (Dissertação de Mestrado), Instituto de Psicologia da Universidade de São Paulo, São Paulo.

Sidman, M. (1976). Táticas da pesquisa científica: avaliação dos dados experimentais na Psicologia (M. E. Paiva, Trad.) São Paulo: Brasiliense.

Sidman, M. (2005). A análise do comportamento humano em contexto. Revista Brasileira de Análise do Comportamento, 1, 125-133.

Simonassi, L. E., Tizo, M., Xavier, V. P. P., \& Rocha, T. C. (2010). Sobre classes de operantes: os casos de nomeação e agrupamento. Psicologia IESB, 2, 13-15.

Skinner, B. F. (1931). The concept of the reflex in the descriptions of behavior. Journal of General Psychology, 5, 427-458.

Skinner, B. F. (1935). The generic nature of concepts of stimulus and response. Journal of General Psychology, 12, 40-65.

Skinner, B. F. (1938). The behavior of organisms. New York: D. Appleton-Century Crofts.

Skinner, B. F. (1969). Contingencies of Reinforcement. New York: Appleton-Century-Crofts.

Schick, K. (1971). Operants. Journal of the Experimental Analysis of Behavior, 15, 413-423.

Staddon, J. E. R. (1969). Asymptotic behavior: the concept of the operant. Psychological Review, 79, 377-391.

Stein L., Xue, B. G., \& Beluzzi, J. D. (1993). A cellular analogue of operant conditioning. Journal of Experimental Analysis of Behavior, 60, 41-53.

Todorov, J. C. (2002). A evolução do conceito de operante. Psicologia: Teoria e Pesquisa, 18, 123-127.

Todorov, J. C. (2012). Sobre uma definição de comportamento. Perspectivas em Análise do Comportamento, 3, 32-37.

Todorov, J. C., \& Henriques, M. B. (2013). O que não é e o que poderia vir a ser comportamento". Revista Brasileira de Análise do Comportamento. 9(1), 74-78.

Tonneau, F. (2013). Behavior and the skin. Revista Brasileira de Análise do Comportamento. 9(1), 66-73.
Tourinho, E. Z. (2006). Relações comportamentais como objeto da psicologia: algumas implicações. Interação em Psicologia, 10, 1-8.

Watson, J. B. (1913). Psychology as a behaviorist views it. Psychological Review, 20, 158-177. 